\title{
ساعات الرضاعة الطبيعية للأم العاملة فى قانون العمل البحرينى بين النظرية و التطبيق
}

$$
\text { د/ نعيمة فرج عبدالنبى }
$$


(.د.نعيمة فرج عبدالنبى) ساعات الرضاعة الطبيعة للام العاملة فى قانون العمل البحرينى

\section{عنوان البحث}

\section{ساعات الرضاعة الطبيعية للأم العاملة فحى قانون العمل البحريني}

\section{بين النظرية والتطبيق}

\section{المقدمة}

تحتفل كل دول العالم تقريبا بالأسبوع العالمى للرضاعة الطبيعية كل عام مابين

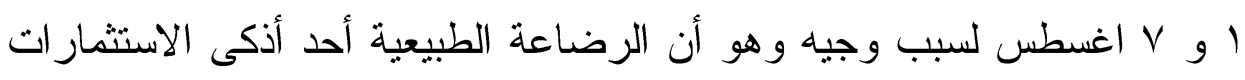

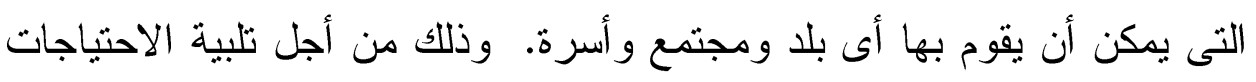
الخاصة للحفاظ على صحة الأم و الطفل اللذين يعتبران الأساس فى تكون الأسرة

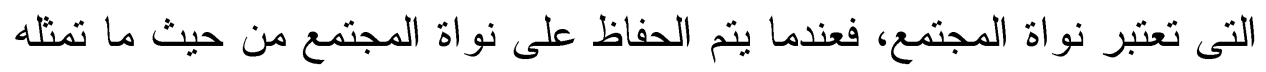

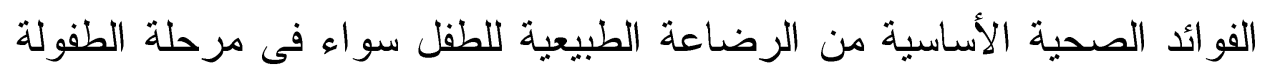

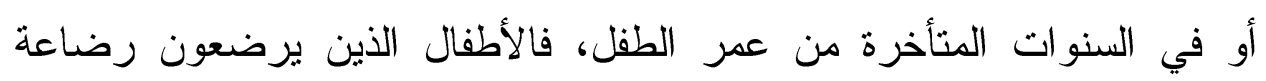
طبيعية هم أقل عرضة لمجموعة من الأمراض الخطيرة، كذلك الفوائد الصحية

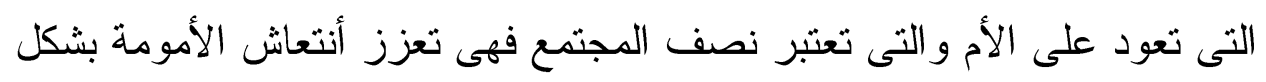
أسر ع ولها العديد من المز ايا و الفو ائد الصحية. 
(د.نعيمة فرج عبالنبى) ساعات الرضاعة الطبيعية للام العاملة فى قانون العمل البحرينى

قد سعت قو انين العمل على مدى سنوات عديدة وفي بلدان مختلفة لتوفير ظروف

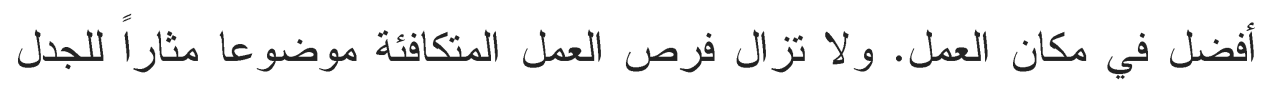
في العديد من الدحافل الاجتماعية والاقتصادية والسياسية والتعليمية على الصعيدين المحلي والدولي وفي هذا السياق، تسعى النساء العاملات لإحداث تغييرات إيجابية في سياسات العمل بغية التقليل - إلى أدنى حد ممكن- من وني التمييز في جميع القطاعات سواء في القطاع العام أو الخاص.

وستسلط هذه الدراسة الضوء على الوضع السابق والحالي لقوانين العمل البحرينية فيما يتعلق بالأمهات العاملات، وذلك عن طريق تحليلها ومقارنتها لهاه التهاه بالسياق الأوسع للقانون الدولي لحقوق الإنسان.

تحاول هذه الدراسة تقديم إسهامات جذرية وعملية للنظام القانوني البحرينى الحالي، ويمكن أن تؤدي النتائج التي نتوصل إليها وتوصياتها اللاحقة إلى تحسين قو انين العمل المتعلقة بساعات الرضاعة الطبيعية التي تفيد الأمهات العاملات في

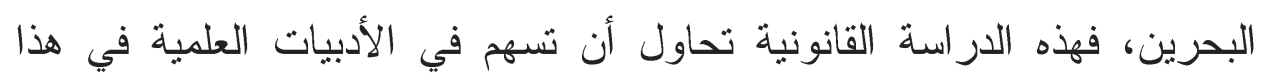
المجال والرفع من مستوى معايير حقوق الإنسان، فضلا عن تقديم بعض الفض

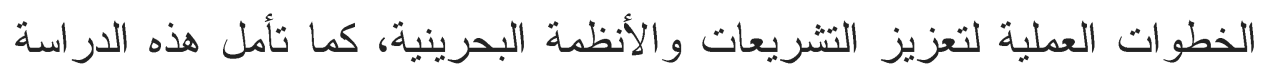
أن تعود بالنفع على النساء البحرينيات وأن نوفر لهن سبل التتع بحقوقهن كأمهات وكنساء عاملات مستقلات بمكنهن القيام بدور فعال في المجتمع

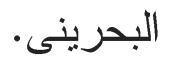


(د.نعيمة فرج عبالنبى) ساعات الرضاعة الطبيعية للام العاملة فى قانون العمل البحرينى

و إذا ما نفذت هذه التغييرات، سيكون لها أثز إيجابي على الاقتصاد البحرينى من خلال زيادة معدلات مشاركة المرأة في القوى العاملة، والسماح لهن بهن بتقديم

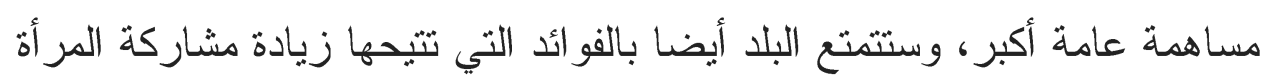

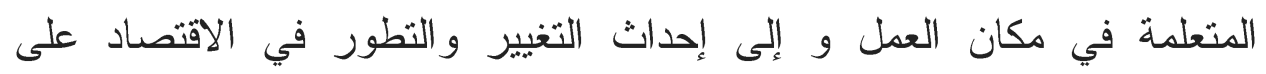
المستوى الوطني من خلال تثجيع أي تعديلات يكثف عنها البحث المطلوب في القانون البحرينى - من حيث النظرية والتطبيق - وهما ضروريان لتبسير تمتع مانع

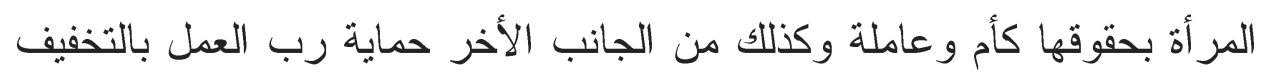

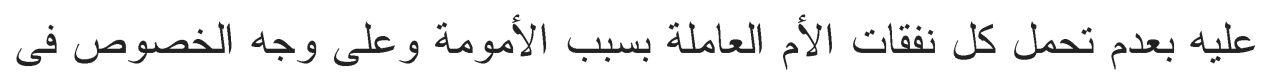

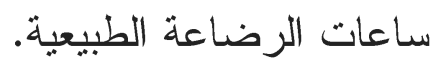

\section{هدف البحث:}

الغرض من هذا البحث هو تسليط الضوء على مدى تمتع الأم العاملة بحقها فى

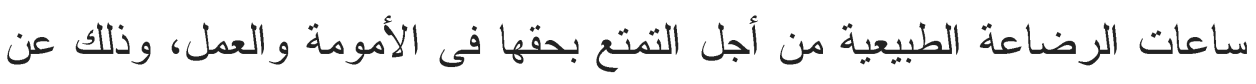
طريق المقابلات الثخصية مع النساء العاملات وذلك من أجل تقييم أكثر اكتمالا لمدى تحقيق الهدف من ساعات الرضاعة الطبيعية للأم العاملة وطفلها عمليا،

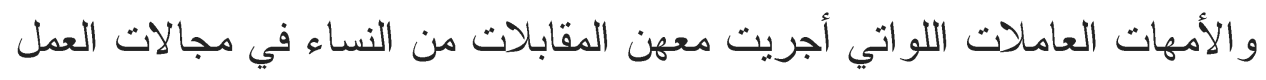
الأكثر شيوعا في البحرين في القطاع الخاص، وذلك من أجل وضع توصيات شاملة للنظوير في النظام القانوني البحرينى. منهية البحث: 
(د.نعيمة فرج عبالنبى) ساعات الرضاعة الطبيعية للام العاملة فى قانون العمل البحرينى

منهج البحث المنبع هو التعمق في القوانين التى لها علاقة بموضوع البحث وتحليهلها والنظر فى ددى تو افقها مع مبادئ حقوق الانسان، كذلك تتبع هذه الدراسة منهج جمع البيانات النوعية الأصلية من خلال إجراء مقابلات شبه

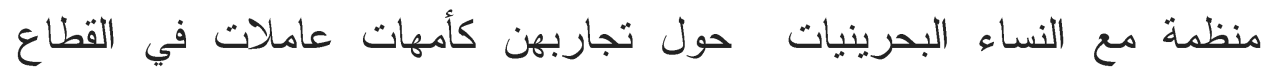
الخاص، ويشمل هذا التصميم نوعا مرنا من المقابلات التي يبدأ فيها القائم

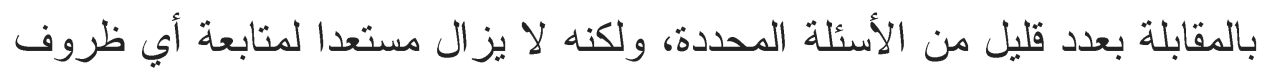
مثيرة للاهتمام قد يكون لها دور للتطور، وتحقيقا لهذه الغاية نستخدم أسئلة مفتوحة.

\section{خطة البحث:}

بركز هذا البحث على أهمية الرضاعة الطبيعية للأم والطفل و المجتمع وذلك من خلال مناقثة هذه الأهمية من خلال القرآن الكريم و السنة النبوية و القانون ومدى

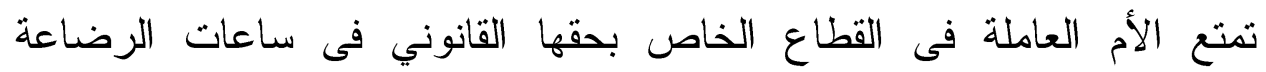
الطبيعية من الناحية النظرية والعملية، لذلك تم تقسيم البحث إلى مبحثين: ففي المبحث الأول سنناقش أهمية الرضاعة الطبيعية فى ثلاث مطالب: المطلب الأول

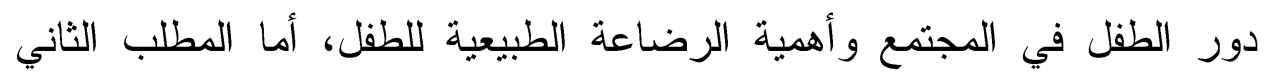
سنتطرق فيه لدور المرأة في المجتمع وأهمية الرضاعة الطبيعية للأم، والمطلب

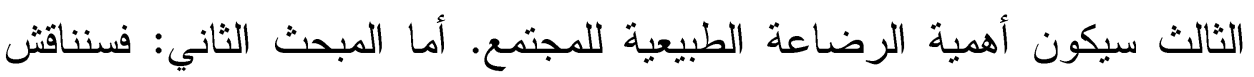
الحماية القانونية ( التشريعية) للحق فى الرضاعة الطبيعية وذلك فى ثلاث 
(د.نعيمة فرج عبدالنبى) ساعات الرضاعة الطبيعية للام العاملة فى قانون العمل البحرينى

مطالب رئيسية: المطلب الأول الحق في الرضاعة الطبيعية في الثريعة

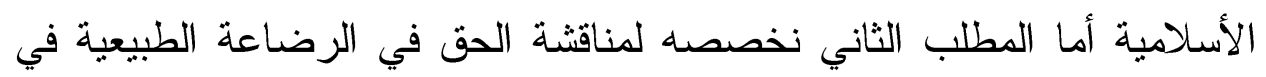

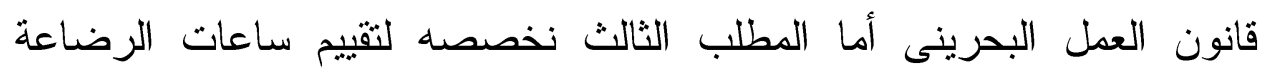
الطبيعية بين النظرية و التطبيق.

\section{المبحث الأول}

\section{أهمبة الرضاعة الطيعية}

إن الرضاعة الطبيعية تحقق فوائد صحية واجتماعية واقتصادية كبيرة لكل من الأم و الطفل و المجتمع،(' )وقد نم اكتثاف أن فترات الرضاعة الطبيعية الأطول

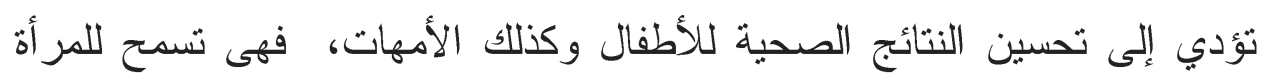

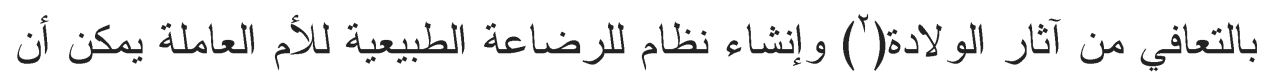
يقلل من مخاطر مختلف النتائج الصحية الضارة وهذا بدوره يعتبر أكبر إنجاز

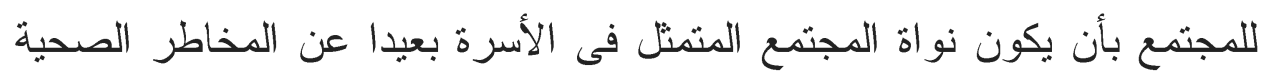

'- منيركر ادشة، العوامل المؤثرة في الرضاعة الطبيعية فى المجتمع الأردني: دراسة كمية

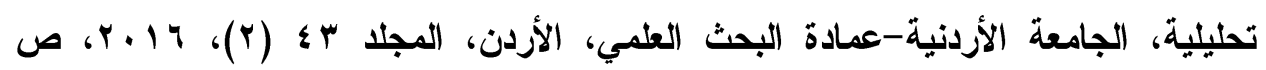
.$v \circ 0$

r - محم بورباب، الإعجاز التشريعي في الحث على الرضاعة الطبيعية، مجلة الاقتصاد

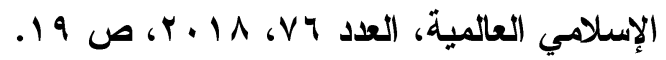


(د.نعيمة فرج عبدالنبى) ساعات الرضاعة الطبيعية للام العاملة فى قانون العمل البحرينى

الضارة،(' )ومن ثم سنتطرق فى هذا المبحث لأهمية الرضاعة الطبيعية للطفل و الأم و المجتمع، في ثلاثة مطالب.

\section{المطب الأول}

\section{دور الطقل في المجتمع وأهمية الرضاعة الطبعية للطقل}

قبل التطرق لأهمية الرضاعة الطبيعية للطفل ينبغي تحديد أهمية الطفل للمجتمع و الدور الرئيسى الذي يلعبه ثم التطرق إلى أهمية الرضاعة الطبيعية بالنسبة له، ولذا سنبحث هاتين النقطنين تو اليا.

\section{القرع الأول}

\section{أهمية الطقل للمجتمع والدور الرئيسى الأي بلِعبه}

نظرًا لأن الأطفال هم حاضر ومستقبل كل دولة، فإن لديهم احتباجات وحقوقًا وقيمة جوهرية يجب الاعتر اف بها ودعمها.(' )وكما كتبت ديان و ايتهيد: إن أطفال اليوم ليسوا أطفال اليوم فحس، بل يمثلون مستقبل كل أمة، على هذا

Association for Childhood Education International and US -

National Committee of the World Organization for Early Childhood, 'Global Guidelines for Early Childhood Education and Care in the $r^{\text {st }}$ Century' (ACEI-OMEP, $r \ldots$ ) '. 
(د.نعيمة فرج عبدالنبى) ساعات الرضاعة الطبيعية للام العاملة فى قانون العمل البحرينى

النحو، يجب دعم حقوقهم واحتياجاتهم، ولكن الأهم من ذلك، يجب الاعتر اف "بقيمتهم الجوهرية" كائنات بشرية في حد ذاتها. إن مكانتهم الصغيرة، ووضعهم المعيّن، وضعفهم، لا تعني أنهّم يجب أن يكونوا أقل معاملةً من غيرهم من البشر الذين بصادف أن يكونوا بالغين. وبالفعل، فإن ضعفهم الشديد يمنحهم وضعا خاصا، فهذا يتطلب على سبيل المثال، منحهم رعاية خاصة فيما يتعلق بصحتهم ورفاهيتهز ووكما أثارت و ايتهيد، فإن الأطفال بحتلون مكانة فريدة في المجتمع فيجب أن يُعترف لهح بمكانتهم ويحترمهم. (')

أطفال اليوم هم "صناع القرار و القادة في الجيل القادم ... وسيشكلون مستقبل المجتع وثقافتة ولذلك من المهز حماية حقوقه الأساسية والحفاظ عليها حتى يتمكنوا من النمو والتطور لتحقيق كامل إمكاناتهم، بهذه الطريقة فقط يمكن للمجتمع و أعضائه الوصول إلى إمكانياتهم الفردية و الجماعية، وهكذا فإن الفهر الصحيح، وضمان حقوق الأطفال لضمان نموهم الصحي كبشر هو هدف

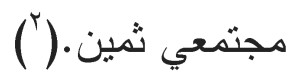

Diane Whitehead, 'Convention on the Rights of the Child' ( $r$. q q) -' $\wedge \odot(r)$ Childhood Education, I $\vee \wedge$.

Robert Karolis, The Convention on the Rights of the Child: The Making of a Deception (Bennett's Printing, 199.) ( $r$ l page booklet). See also M Siraj Sait, 'Islamic Perspectives on the Rights of the Child' in Fottrell Deirdre (ed), Revisiting Children's Rights: 1. Years of the UN Convention on the Rights of the Child (Kluwer Law International, r... $), r$. 
(د.نعيمة فرج عبدالنبى) ساعات الرضاعة الطبيعية للام العاملة فى قانون العمل البحرينى

ومن خلا الاعتبارات السابقة كانت الحاجة الى اتفاقية دولية تحمى الطفل من كل الجوانب فكان أن اعتمدت الجمعية العامة للأمم المتحدة اتفاقية حقوق الطفل

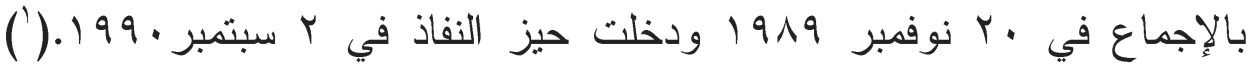
و هي اتفاقية مهمة تتطوي على آثار في السياسات والممارسات، فهي المعاهدة الدولية الرئيسة التي تنتاول حقوق أطفال العالم.(' )وتوفر الإطار القانوني الأكثر شمولاً لحقوق الإنسان الأساسية للأطفال في كل مكان.(") اتفاقية حقوق الطفل هى مؤتمر مشهور ومحترم في جميع أنحاء العالم. يحتفل الباحثون و المدافعون عن حقوق الأطفال على حد سواء بالنهج المبتكر لحقوق الطفل ويثثون عليه.(")

هنالك عدة جو انب رئيسية تجعل اتفاقية حقوق الطفل اتفاقية فريدة و عملية ومقبولة عالمياً، حيث يصل عدد الدول التى انضمت إلى هذه الاتفاقية إلى

- V اعتمدت وعرضت للتوقيع والتصديق والأضمام بموجب قرار الجمعية العامة رقم

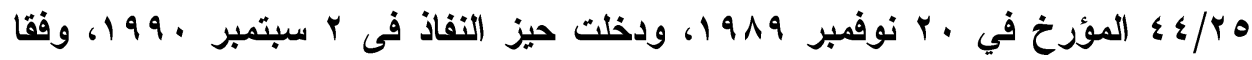

للمادة

Robin S Mama, 'Needs, Rights, and the Human Family: The $-^{r}$ Practicality of the Convention on the Rights of the Child' $\left(r \cdot r^{\cdot}\right)$ $\wedge १(\diamond)$ Child Welfare, I $\vee$.

Diane Whitehead, 'Convention on the Rights of the Child' $\left(r_{\cdots} q^{q}\right)-^{r}$ $\wedge \bullet(r)$ Childhood Education $1 \vee \wedge$.

" - Doris E Buss, "'How the UN Stole Childhood": The Christian Right and the International Rights of the Child' in Jo Bridgeman and Daniel Monk (eds), Feminist Perspectives on Child Law (Cavendish, r... , rAr. 
(د.نعيمة فرج عبدالنبى) ساعات الرضاعة الطبيعية للام العاملة فى قانون العمل البحرينى

9 ادولةًا(')ومن ضمن هذه الدول مملكة البحرين فبموجب القانون رقم 17

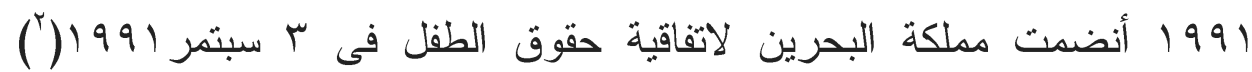

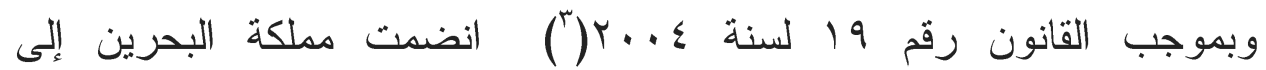
البروتوكولين الاختباريين بشأن اشترآك الأطفال في الصراعات المسلحة وبيع الأطفال وبغاء الأطفال والمواد الإباحية عن الأطفال الملحقين باتفاقية الأمم المتحدة لحقوق الطفل. و الاتفاقية لها أهمية فريدة وأهمها ما نصت عليه المادة الثالثة من الاتفاقية وهو يجب أن تكون مصالح الطفل العليا أى مصلحة الطفل هى الاعتبار الأساسي.(ء) وتهدف الى "دعم الأطفال والعائلات وتوفير التدابير التي تمكن الطفل من الاستعداد في نهاية المطاف لقيادة حياة كاملة". ( )

\section{الفرع الثاني}

أهمبة الرضاعة الطبيعية للطفل

) $9 / 4 \cdot 1 \leqslant / r$ - Convention on the Rights of the Child $19 \wedge q$, ( 1$)$ https://treaties.un.org/Pages/ViewDetails.aspx?src=TREATY\&mtdsg no=IV-1 1 \&chapter $=$ \& \&lang=en

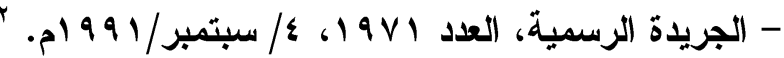

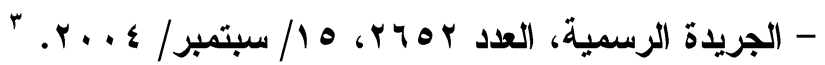

Convention on the Rights of the Child (CRC). See also Whitehead, - q, I $\vee \wedge$. above $\mathrm{n}$

Robin S Mama, 'Needs, Rights, and the Human Family: The Practicality of the Convention on the Rights of the Child' $(r+1 \cdot)$ . I १ ^৭(॰) Child Welfare 
(د.نعيمة فرج عبدالنبى) ساعات الرضاعة الطبيعية للام العاملة فى قانون العمل البحرينى

الرضاعة الطبيعية حق أساسي للطفل، يحمي القانون الدولي حق الحصول على لبن الثذي وهو - بحكم النظرية على الأقل - محمي بشكل صارم ويتم تضمينه في الحقوق الراسخة وغير المتنازع عليها في الغذاء و الصحة والحياة، علاوة على ذللك يتم الاعتر اف بها دوليا كدق للأطفال و النساء العاملات، ولأن كل من هذه وله

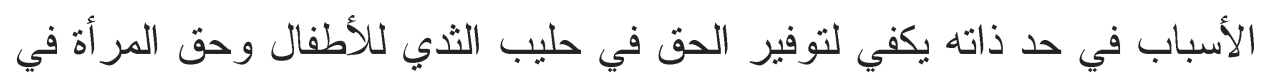

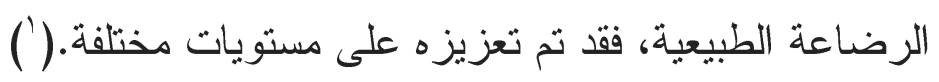

جميع البشر لديهم الدق في الغذاء، "الغذاء الكافي" على وجه الدقة، وأكبر "طعام"

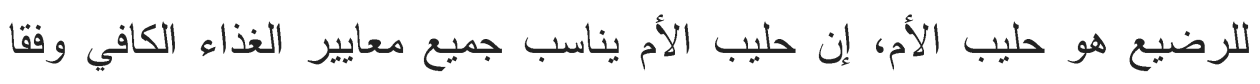

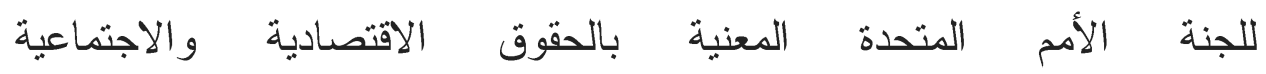
و الثقافية(Y) ب (CESCR)(هذه المعايير هي: الجودة والكمية و السلامة و إمكانية الوصول و المقبولية. وبدون حليب الثدي، لا يمكن وجود هذا و لا يمكن ممارسة

\section{' - Olivia Ball, 'Breastmilk is a Human Right' $(r \cdot 1 \cdot) \backslash \wedge(r)$}

\section{Breastfeeding Review 9 , 9.}

r - أعتمد وعرض للتوقيع و التصديق والاضمام بموجب قرار الجمعية العامة - للأمم

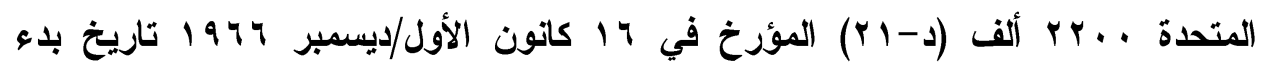

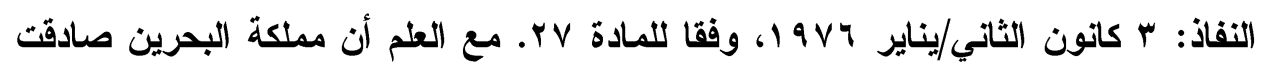

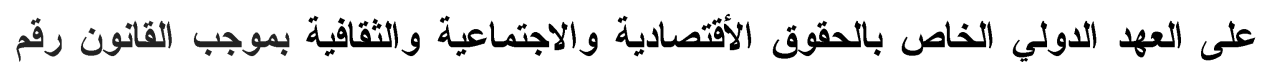

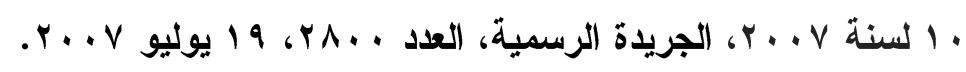


(د.نعيمة فرج عبدالنبى) ساعات الرضاعة الطبيعية للام العاملة فى قانون العمل البحرينى

هذا الحق دون إجازة أمومة،(') وبعد انقضائها يمارس هذا الحق عن طريق ساعات الرضاعة الطبيعية.

وقد أظهرت الأبحاث أن الرضاعة الطبيعية لها فو ائد على صحة الطفل، ومن خلال هذه الأبحاث ثبت أن الرضاعة الطبيعية تحمي الأطفال من السمنة بالإضافة إلى الحماية من السمنة في المر احل اللاحقة من الحياة.(r)

وجد أن انتشار السمنة يكون أعلى بين الأطفال الذين لم يرضعوا أبدًا مقارنة بالذين رضعوا من الثدي بغض النظر عن العوامل الاجتماعية والاقتصادية الأخرى، الرضاعة الطبيعية مههة خلال المر احل الأولى من الحياة.( )كان تأثير الرضاعة الطبيعية على الحد من مخاطر السمنة في مرحلة الطفولة و اضحا بغض النظر عن مرض السكري أو حالة الوزن التى قد تعانى منها بعض الأمهات،(؛) وخاصة إذا كانت الرضاعة الطبيعية لفترة طويلة.( ) الرضاعة

,'1.1. Olivia Ball, Ibid -'

S Arenz et al, 'Breast-feeding and Childhood Obesity - A -

Systematic Review' ( $\uparrow \ldots \varepsilon) \uparrow \wedge$ International Journal of Obesity $\mid r \leq \vee$, iros.

Christopher G Owen et al, 'Effect of Infant Feeding on the Risk of -" Obesity across the Life Course: A Quantitative Review of Published

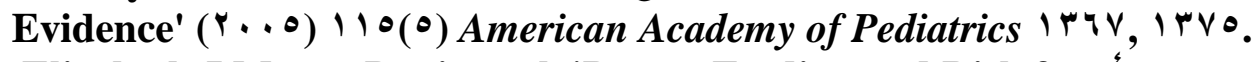
Elizabeth J Mayer-Davis et al, 'Breast-Feeding and Risk for -"

Childhood Obesity: Does Maternal Diabetes or Obesity Status

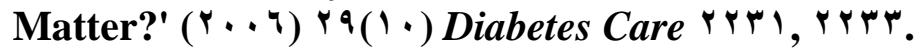

Laurence M Grummer-Strawn and Zuguo Mei, 'Does -

Breastfeeding Protect Against Pediatric Overweight? Analysis of Longitudinal Data from the Centers for Disease Control and 
(د.نعيمة فرج عبدالنبى) ساعات الرضاعة الطبيعية للام العاملة فى قانون العمل البحرينى

الطبيعية فى المرحلة المبكرة من عمر الطفل تحميه من تأخر النمو الجسمى و الذى يعتبر من أصعب المشاكل التى تؤثز على صحة الطفل النفسية وو الديه(') ويتمنل أهم دور للرضاعة الطبيعية في حماية الأطفال من خلال توفير بيئة صحية للنمو، (r) كما آنها تضمن الرفاهية المستمرة للطفل، وكذلك جيل المستقبل الصحي، فالرضاعة الطبيعية تعمل على خلق طفل فريدٍٍ و متميزٍ من نوعها؟ (الذي يعد رصيدا قيما لأي مجتمع.(" ) المطاب الثاني دور المر أة فى المجتمع وأهمبة الرضاعة الطبعية للأم

Prevention Pediatric Nutrition Surveillance System' $(r \ldots \varepsilon) \backslash \uparrow(\uparrow)$ Pediatrics $\wedge 1, \wedge \circ$. '- عامرمحد علي الأميري (وأخرون)، تأخر النمو الجسمي لاى أطفال الرياض وعلاقته

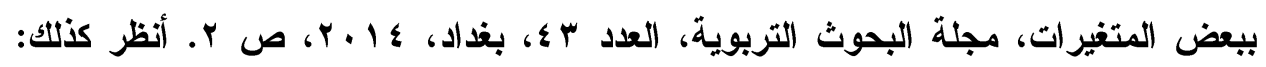
مخلوف وردة و فسيان حسين، بعض المحددات النفسية والثقافية لممارسة الرضاعة لونة

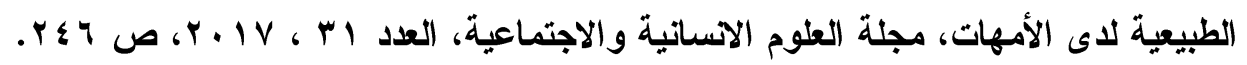

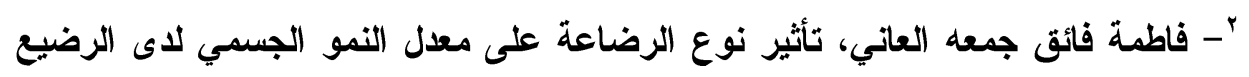

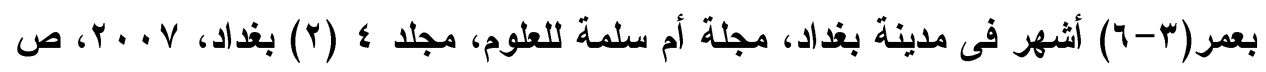
. بs .

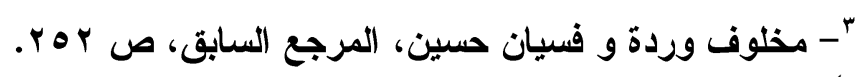
Lawrence M Berger, Jennifer Hill and Jane Waldfogel, 'Maternity Leave, Early Maternal Employment and Child Health and Development in the US' (February $\left.{ }^{\prime} \ldots .0\right) 110(0.1)$ Economic rrJournal F 
(د.نعيمة فرج عبدالنبى) ساعات الرضاعة الطبيعية للام العاملة فى قانون العمل البحرينى

الرضاعة الطبيعية لها عدة مزايا للأم ولكن قبل توضيح هذه الفو ائد أو المزايا

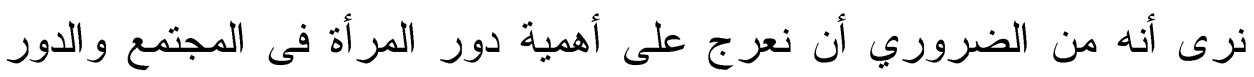
الرئيسي الذي تلعبه فى (الفرع الاول) من هذا المطلب، ثم نعرج على أهنى أهمية الرضاعة الطبيعية للأم فى (الفرع الثاني). الفرع الأول

\section{أهمبة المر أة للمجتمع والدور الرئيسى الذي تلعبه}

المرأة تمثل نصف المجتمع وهي المسئولة عن تربية النصف الآخر، ولهذا كرم الإسلام المرأة بأن جعل لها فى كتاب اله العزيز سورة كاملة باسم سورة النساء

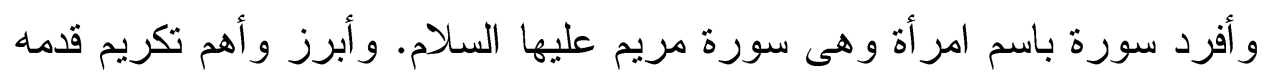

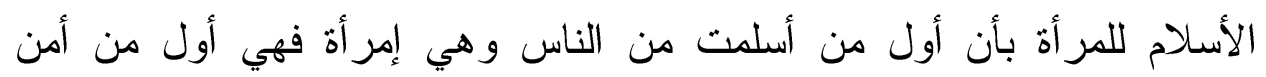
بالرسول صلى الله عليه وسلم وهى السيدة خديجة رضي الله عنها، وأول من من من الهن

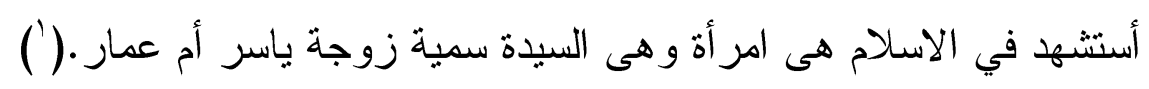
و المرأة لها دور كبير فى المتمع داخل البيت كأم وبنت وأخت وعمة وخالة

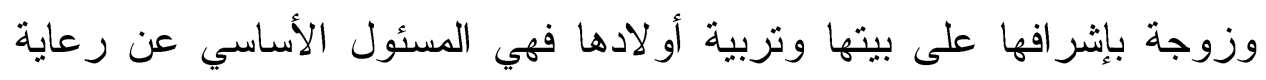
الأسرة وغير ذلك من الأمور.

Mahmood Ahmad Ghadanfar, Great Women of Islam: Who were -' given the good news of paradise, First Edition, Darussalam, Riyadh Saudi Arabia, $, \ldots 1, r, 1 \wedge 1$. 
(د.نعيمة فرج عبدالنبى) ساعات الرضاعة الطبيعية للام العاملة فى قانون العمل البحرينى

وقد لوحظ على الصعيد الدولي أنه بينما ازدادت مشاركة المرأة في مكان العمل زيادة كبيرة في العقود الأخيرة، فإنها تواصل تحمل المسؤوليات الأساسية عن العمل غير المأجور في الأسرة، بما في ذلك توفير الرعاية لأفر اد الأسرة والمهام المنزلية. (')إن عمل المرأة غير المأجور أمر حيوي لاستمرار عمل ورفاهية المجتمع بأكمله لأنشطتها غير الاقتصادية ... كما أن تمكين ورعاية وصيانة كل فرد في المجتمع، يدعم الصحة المجتمعية و البقاء.(') ووجدت در اسة أجريت عام ل99 أجريت باستخدام اليوميات الزمنية) أنه بينما قضت النساء وقتا أقل في

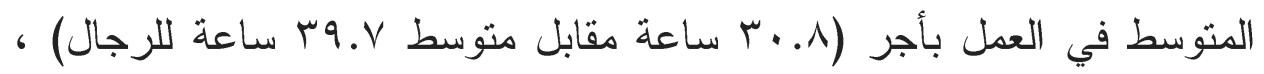

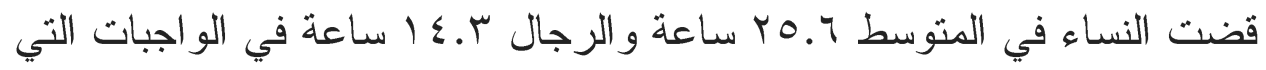
تدور حول رعاية الأسرة، بما في ذلك التسوق والأعمال المنزلية ورعاية الأطفال، وكثفت الدراسة عن عدم توازن في ساعات العمل المدفوعة على أساس نوع الجنس والحفاظ على أدوار الجنسين التقليدية بسبب كثرة الرعاية في

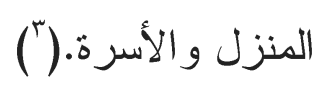

Laura Addati and Naomi Cassirer, 'Equal Sharing of -'

Responsibilities Between Women and Men, Including Care-Giving in the Context of HIV/AIDS' (EGM/ESOR/ $+\cdots \wedge / B P . r$, Division for the Advancement of Women Department of Economic and Social Affairs United Nations, 19 September $r . . \wedge$ ) $r$.

ـ المرجع السابق، ص ع. Melissa A Milkie and Pia Peltola, 'Playing All the Roles: Gender - ${ }^{r}$ and the Work-Family Balancing Act' ( 199 १) 1 ( ( $)$ Journal of Marriage and Family $\leqslant \vee\urcorner$, $\leqslant \vee \wedge$. 
(د.نعيمة فرج عبدالنبى) ساعات الرضاعة الطبيعية للام العاملة فى قانون العمل البحرينى

و المرأة العاملة تعمل من أجل الحفاظ على استقلالها الاقتصادي بالدرجة الاولى، كما أن رغبتها في العمل هي من أجل دعم نفسها و عائلتها كذلك، وعليه فان

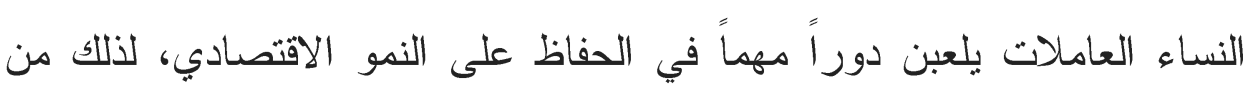
الضروري أن يتم حماية حقهن في إنجاب الأطفال ورعاية الأسرة، فوظيفتها الإجتماعية مهمة للغاية لتحقيق الفائدة العامة للمجتمع.(') الفرع الثاني

أهمبة الرضاعة (لطبيعية للأم

وقد أظهرت الأبحاث أن الرضاعة الطبيعية لها فوائد على صحة الأم. ومن هذه الدراسات أن النساء اللواتي يرضعن أطفالهن رضاعة طبيعية لايهن خطر أقل للإصابة بسرطان الثدي(')وسرطان الرحم و المبيض وتعيد الرحم إلي حالته الطبيعية الذى يتسع ·. مرة أثناء الحمل لارتباط الرضاعة الطبيعية بهرمون

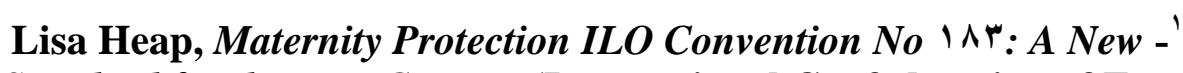
Standard for the New Century (International Confederation of Free Trade Unions (ICFTU), Public Services International (PCI) and . Education International (EI), r.. I) 1

Tongzhang Zheng et al, 'Lactation Reduces Breast Cancer Risk in Shandong Province, China' $(r \ldots)$ lor( 1 r $)$ American Journal of Epidemiology $1 / \curlyvee q, 1 / r$; see also Laufey Tryggvadóttir et al, 'Breastfeeding and Reduced Risk of Breast Cancer in an Icelandic' $(r+1) 10 \leqslant(1)$ American Journal of Epidemiology $r \vee, r q$. 
(د.نعيمة فرج عبدالنبى) ساعات الرضاعة الطبيعية للام العاملة فى قانون العمل البحرينى

الأوكسيتوسين (Oxytocin)(' )(المسئول عن إعادة حجم الرحم ووقف نزيف

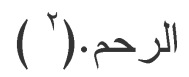

كذلك الرضاعة الطبيعية لها قيمة كبيرة للأم من حيث زيادتها لإفراز هرمون الحليب البرو لاكتين (Prolactin)،(" )وهذا يمنع التبويض ويمنع الحمل مما يساعد الأم على استعادة صحتها وبناء عظامها من جديد و المحافظة على عظمة الحوض لاحقاً.(") وكل هذه الخصائص والميزات للرضاعة الطبيعية تكون فاعلة للنساء اللواتي لديهن فترات أطول فى الرضاعة الطبيعية.

إن حق المرأة في الرضاعة الطبيعية ثم تعزيزه فى مستويات مختلفة، وتفيد ساعات الرضاعة الطبيعية لجميع ( الطفل، المرأة، المجتمع) ولكنها تحمي

'ـ الأوكسيتوسين، هرمون تطلقه الغدة النخامية التي تسبب زيادة انكماش الرحم أثناء

Lothian, Judith A. "The Birth of a Breastfeeding Baby and -

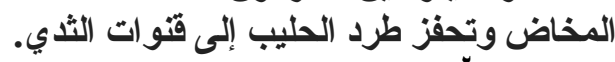

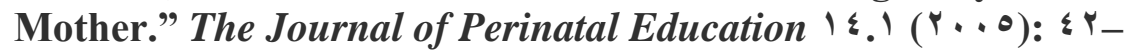
\& ०.PMC. Web. $Y \leqslant$ Apr. $Y \cdot 1 \wedge$.

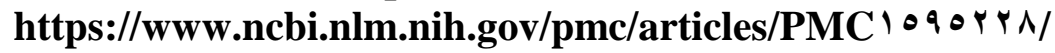
هرمون يطلق من الغدة النخامية الأمامية التي تحفز إنتاج الحليب بعد الولادة. Infant and Young Child Feeding: Model Chapter for Textbooks for Medical Students and Allied Health Professionals. Geneva: World Health Organization; $r \ldots q$. Available from: $r \cdot$ Apr. $r+1 \wedge$ https://www.ncbi.nlm.nih.gov/books/NBK । ¿^৭५०/ 
(د.نعيمة فرج عبدالنبى) ساعات الرضاعة الطبيعية للام العاملة فى قانون العمل البحرينى

بصفة خاصة حق الأمهات العاملات، مما يسمح لهن بالعمل دون تمييز، حيث (') يسمح لهن بالخروج من الوظيفية دون التضحية بالأمن الوظيفي المطلب الثالث

أهمبة الرضاعة الطبعية للمجتمع

إن حماية الأمومة التي تحافظ على صحة الأمهات وأطفالهن وتسمح للنساء بالاستمرار في المساهمة في النمو الاقتصادي للدول أمر مفيد للحكومة، كما أنه يخدم مصالح الحكومة من خلال السماح باستخدام الموارد النادرة في أماكن بديلة ودعم تتمية السكان الأصحاء.(')وتعتبر إجازة الأمومة ومواصلة الرضاعة الطبيعية ذات أهمية كبيرة لأنها تضدن صحة المرأة (التي تشكل أهمية كبيرة في الاقتصاد) و الأطفال (الذين يمثلون الأجيال القادمة).(")

فمن منظور السياسة العامة أو التركيز على الاقتصاد فقط، سيُنظر إليها كقيمة عظيمة وذلك لأن زيادة فترات إجازة الأمومة ومعدلات الإرضاع من الثذي

Lisa Heap, Maternity Protection ILO Convention No $1 \wedge$ r : A New -' Standard for the New Century (International Confederation of Free Trade Unions (ICFTU), Public Services International (PCI) and

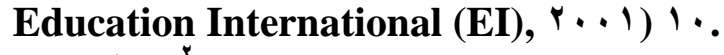

Ibid $1 \cdot .-$

Olena Nizalova, The Economic and Social Consequences of $-^{r}$ Maternity Protection: A Cross-Country Analysis (LLM Thesis,

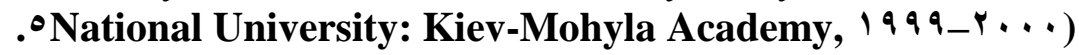


(د.نعيمة فرج عبالنبى) ساعات الرضاعة الطبيعية للام العاملة فى قانون العمل البحرينى

سوف تؤدي إلى الاحتفاظ بالعمالة الماهرة، مما يسمح للنساء-اللواتي ربما يغادرن سوق العمل- بالعودة والمساهمة بخبراتهن، وهذا من شأنه أن يمتل توفيرًا في التكاليف للحكومة والاقتصاد، حيث إن العمالة الماهرة لهؤلاء النساء المتعلمات ستظل قادرة على أن تساهم في خدمة البلا بدلاً من أن تعتمد الدولة النة على العمالة الأجنبية المستوردة، كما سيمثل عائدا استثماريا للدولة التي تكفلت بتعليم هؤ لاء النساء كما أنه سيؤدي إلى الرفع من مستوى المعيشة للأسر.

كذللك الرضاعة الطبيعية مفيدة للاقتصاد الوطنى، حيث تساعد على تقليل تكاليف الرعاية الصحية وتحسين التحصيل الدراسي من حيث تحقق أفضل النتائج فى اختبارات الذكاء(')وقد أثثتت العديد من الدراسات أن الرضاعة الصناعية لها مردود سلبى على صحة الطفل، ومن أهم اسباب تسوس الأسنان عند الأطفال هو هو الرضاعة الصناعية(') وتعتبر الرضاعة الطبيعية أحد الاستثمارات المتاحة العالية المردود، حيث يدر كل دو لار يستثر في دعم الرضاعة الطبيعية نحو مب دو لار ا في شكل عو ائد اقتصادية فى مختلف البلدان المنخفضة والهتوسطة الدخل، وعلى العكس من ذللك يتجلى انخفاض معدلات الرضاعة الطبيعية فى مليارات

- سامر مظهر قنطقي، اقتصاد الرضاعة الطبيعية بين الضو ابط والمصالح، مجلة الاقتصاد

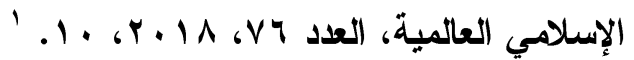

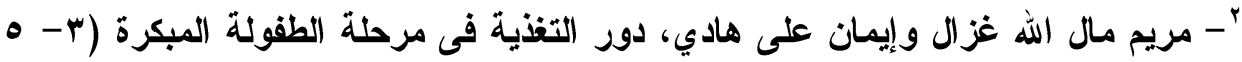
سنوات) وبعض المتغيرات واثرها في اصابة الاطفال بتسوس الاسنان، مجلة كلية التربية التربية

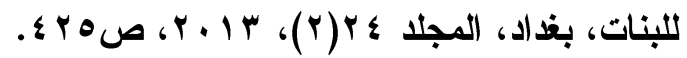


(د.نعيمة فرج عبدالنبى) ساعات الرضاعة الطبيعية للام العاملة فى قانون العمل البحرينى

الدو لار ات التى تمثل خسارة في الانتاجية وتكاليف الرعاية الصحبة الموجهة إلى علاج الأمر اض التي يمكن توقيها وخاصة الأمر اض المزمنة.(' )

\section{المبحث الثاني}

الحمابة القانونية (التشريعية) للحق فى الرضاعة الطبية

ومن خلال ما تقدم عن دور وأهمية الرضاعة الطبيعية للطفل وللأم و المجتمع، فإن القانون- سواء على المستوى المحلي أو على المستوى الدولي - اهتم بضرورة النص عليها ومنحها للأم العاملة لأنها تشكل ضرورة كبرى على مستوى حقوق الإنسان. ومن أجل أعطاء صورة و اضحة لحماية هذا الحق فسيتم التطرق الى الحق فى الرضاعة الطبيعية فى الثريعة الأسلامية، وفى التشريع البحرينى، ثم ساعات الرضاعة الطبيعية بين النظرية و التطبيق وذللك فى ثلاثة

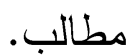

\section{المطب الأول}

الحق فى الرضاعة الطبيعة فى الثربعة الإسلامية

نجد المشرع الحقيقي الذى لا تغيب عنه أى حقبقة هو رب الكون ورب الناس أكد على إلزامية وأحقية الرضاعة الطبيعة فى كتابه العزيز وسنة رسوله الكريم /Organization, $r$ April $r$. $\wedge$ http://www.who.int/dg/en 
(د.نعيمة فرج عبدالنبى) ساعات الرضاعة الطبيعية للام العاملة فى قانون العمل البحرينى

سيدنا محمد صلى الله عليه وسلم. ففى هذا المطلب سنوضح الحق فى الرضاعة الطبيعة فى القرآن الكريم و الحق فى الرضاعة الطبيعية فى الأحاديث النبوية ) الشريفة) وذللك سيكون فى فر عين.

\section{القرع الأول}

\section{الحق في الرضاعة الطبيعية في القرآن الكريم}

منذ أربعة عشر قرنا من الزمان أكد الخبير فى كتابه العزيز الله جل جلاله على حماية الطفل و الأم والمجتمع عن طريق الغذاء الكافي بكل مكوناته المتمثل في الرضاعة الطبيعية وأكد على أهمية الرضاعة الطبيعية، وهذا ما قررته اليوم منظمة الصحة العالمية (WHO) ومنظمة الامم المتحدة للطفولة (UNICEF) فقد أكد النص القرآني على الرضاعة الطبيعية فى سبع سور من القرآن الكريم وهذه السور هى سورة البقرة الآية سبr،(' )سورة النساء الآية سץ،(") سورة الحج

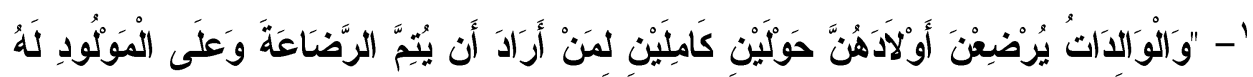

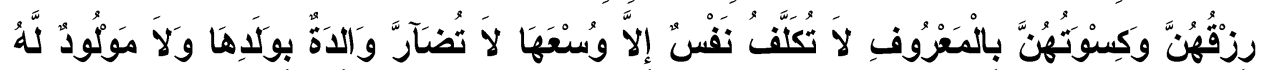

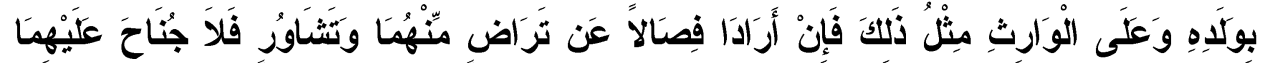

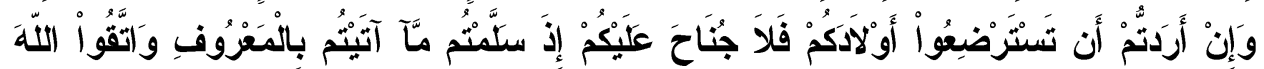

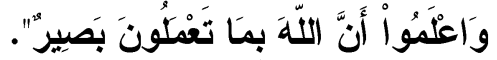

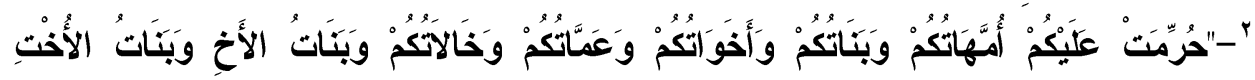

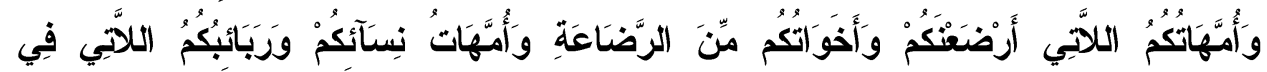

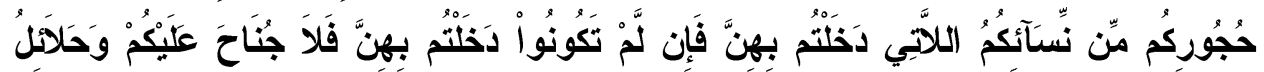


(د.نعيمة فرج عبدالنبى) ساعات الرضاعة الطبيعية للام العاملة فى قانون العمل البحرينى

الآية r((')سورة القصص الآيات ل و و rا،(") سورة لقمان الآية ع ا،(") سورة

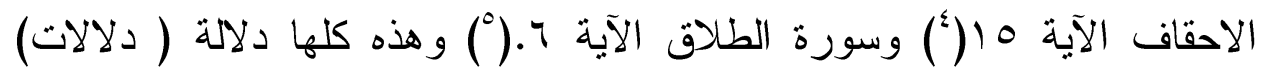
على مدى أهمية ومنفعة الرضاعة الطبيعية للجميع وأهمهم الطفل والأم.

ونذكر أدناه بعضاً من هذه الآيات الكريمة، يقول جل شأنه في كتابة العزيز:

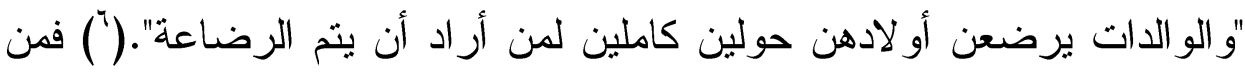

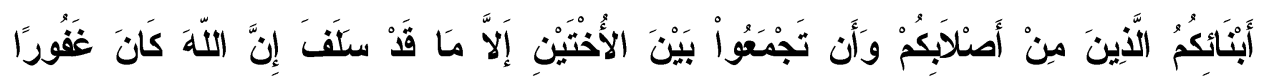

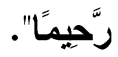

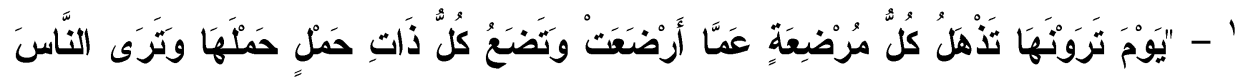

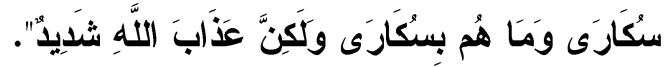

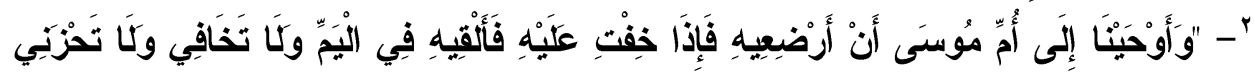

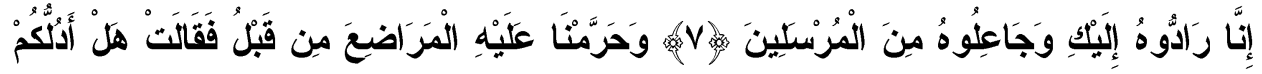

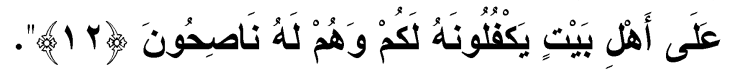

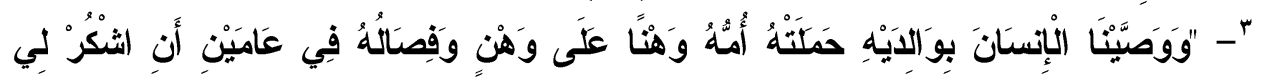

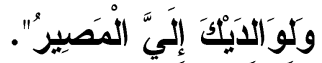

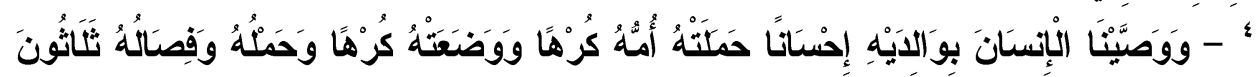

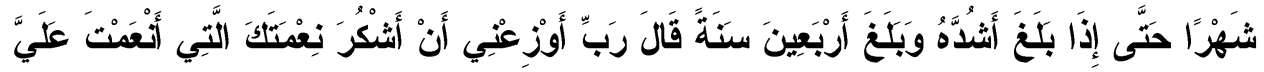

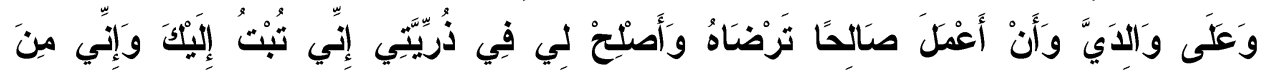

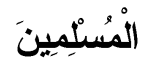

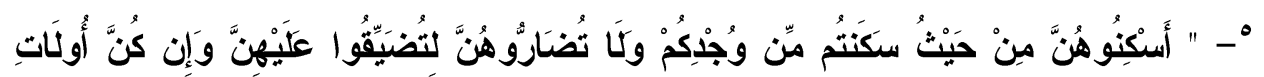

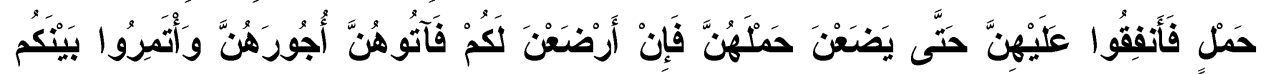

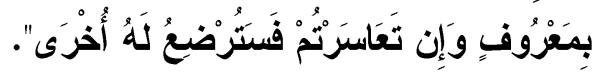

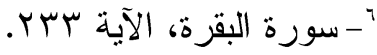


(د.نعيمة فرج عبالنبى) ساعات الرضاعة الطبيعية للام العاملة فى قانون العمل البحرينى

ملاحظة هذه الآية الكريمة نجد واجباً و الزاماً على الأم الرضاعة ولم يكتف بالنص على ذلك فقط بل ذكر التأكيد على مدة الرضاعة عامين كاملين.

فهذا النص الالهي يحمل مفاهيم مهمة جدا تتمثل في أن على الأم التزاماً وواجباً

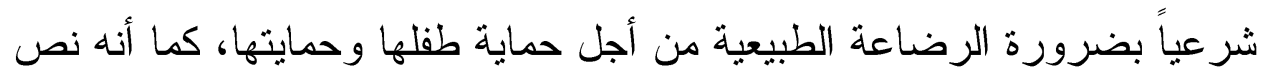
على الحيز الزمنى لهذه الرضاعة ولم يتركها مفتوحة بل حددها بحولين كاملين. و هذا تأكيد من العزيز الحكيم على أهية حليب الأم الذى فيه كل المكونات، والله سبحانه وتعالى حدد مدة الرضاعة الطبيعية لددة عامين كاملين لأن هذه أهم مرحلة فى عمر الطفل التى يبنى وينمو فيها جسده حتى يكون صحيحا معافا من

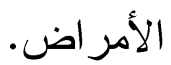

ولم يكتف العزيز الحكيم جل شأنه على النص على مدة الرضاعة فقط بل حدد فى الآية ع ا من سورة لقمان متى ينم أنهاء الرضاعة أى حدد الوقت الذى

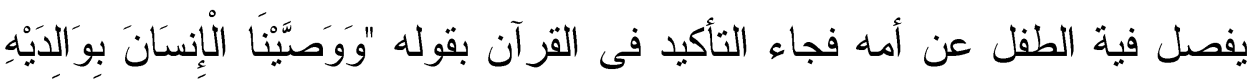

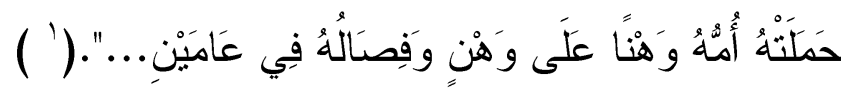

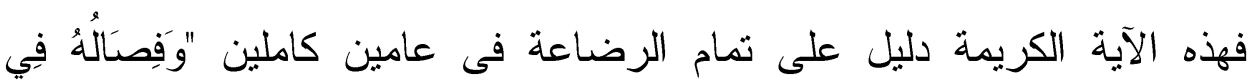
عَامَيْن". أى فطامه بعد السنتين وفى الوقت الحاضرتأكد بأن هذه الددة علميا توفر 
(د.نعيمة فرج عبالنبى) ساعات الرضاعة الطبيعية للام العاملة فى قانون العمل البحرينى

أكبر و أفضل حماية للطفل والأم، وكل الأبحاث أجمعت على أنه أفضل غذاء للطفل كامل فيه كل المكونات هو حليب أمه.(' )

\section{القفرع الثاني}

\section{الحق في الرضاعة الطيعية فى الأحاديث النبوية}

لاجرم أن السنة النبوية هي المصدر الثاني من مصادر التثريع الإسلامي فلها حجيتها و منزلتها في حياة المسلمين مثل القرآن الكريم لأن رسول الله صلى الله عليه وسلم في كل أحاديثه يشرع لنا من عند اله تعالى وليس من عند نفسها،

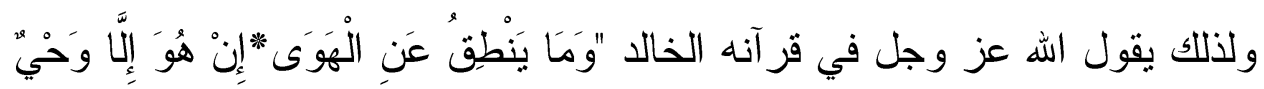

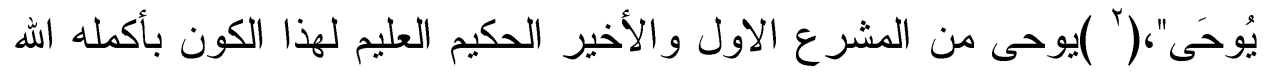
جل جلاله. وتأكيدا على حجية السنة النبوية ومنزلة أحاديث الرسول صلى الله

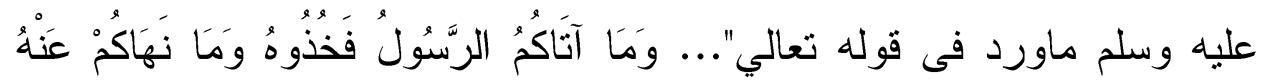

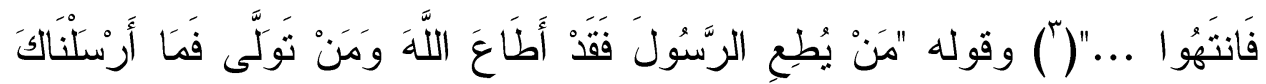

'- سامر مظهر قنطقجي، المرجع السابق، ص ع ا، كما يرجى الرجوع الى ما تم شرحة وتوضيحة فى الفرع الثاني من المطلب الأول من المبحث الاول عن أهمية الرضاعة الطبيعية الثراية للطقل.

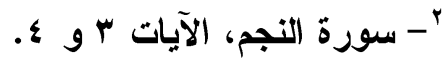

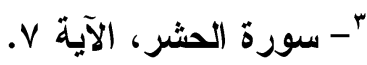


(د.نعيمة فرج عبدالنبى) ساعات الرضاعة الطبيعية للام العاملة فى قانون العمل البحرينى

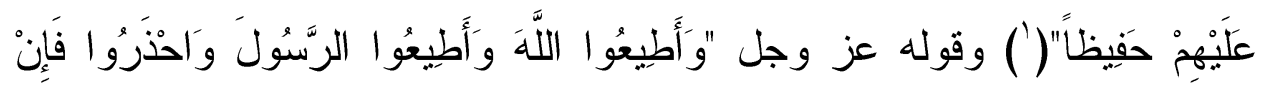

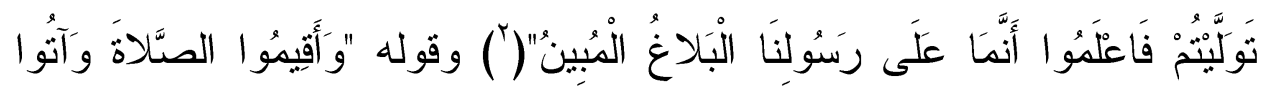

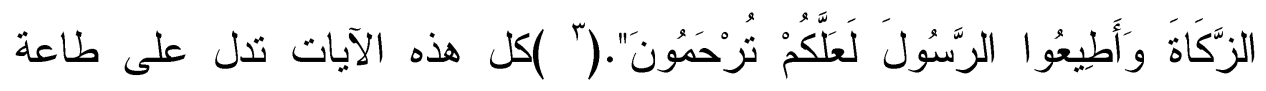

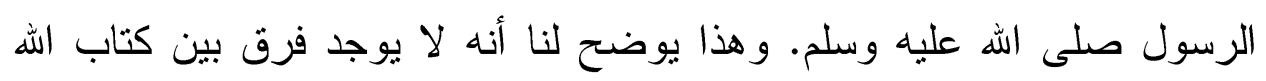

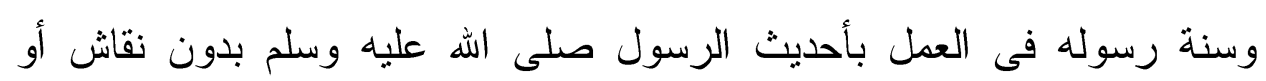

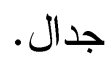

وقد أكدت السنة النبوية على الحق فى الرضاعة الطبيعية ومن هذه الأحاديث النبوية الحديث الثريف عن النبي صلى الله عليه وسلم "نعمت المرضعة وبئست الفاطمة"(أ)فهذا تحذير من الرسول صلي اله عليه وسلم على خطورة نرك الرضاعة الطبيعية للأم. وكذلك عن رسول الله صلى الله عليه وآله وسلم قال"ليس للصبي خير من لبن أمه". كذللك قال "جعل الله رزقه من ثدى أمه فى

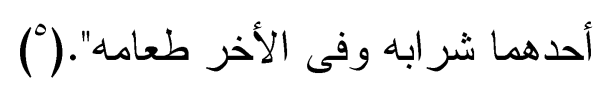

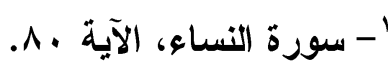

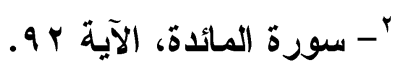

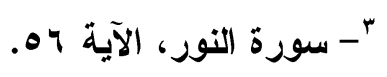

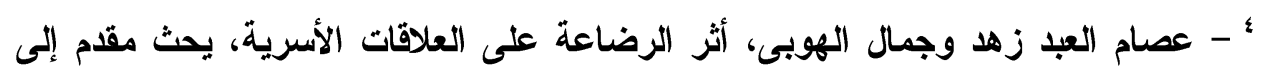

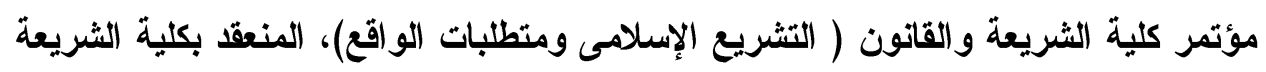

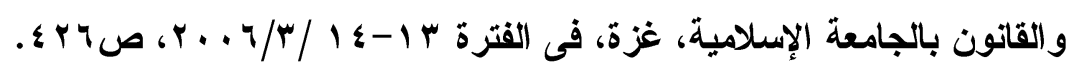

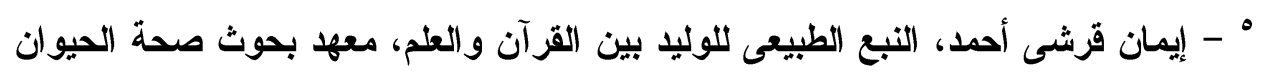

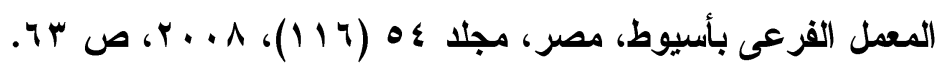


(د.نعيمة فرج عبدالنبى) ساعات الرضاعة الطبيعية للام العاملة فى قانون العمل البحرينى

فمن خلال هذه الأحاديث التى تبين مدى أهمية الرضاعة الطبيعية للطفل والأم

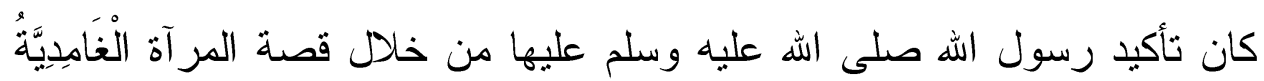
الحبلى من جريمة الزنا التى أتت إلى رسول اله صلى الله عليه وسلم تائبة تريد

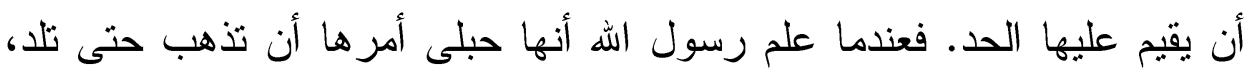

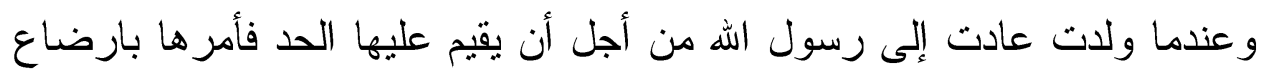
طفلها حتى فطامه، وبعد فطامه عادت وفى يد طفلها قطعة خبز من أجل أن تبين للرسول إن الصبى فطم و أصبح يعتمد على نفسه فى الاكل، ثم أقام عليها

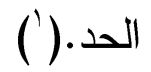

هذه القصة توضح لنا مفهوماً كبيراً ودرساً نبوىاً اكبر على الرحمة النبوية وترسيخ المبادئ الإنسانية لخدمة البشرية، فحرص الاسلام على الطفل من حيث

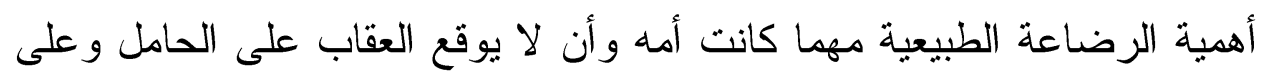

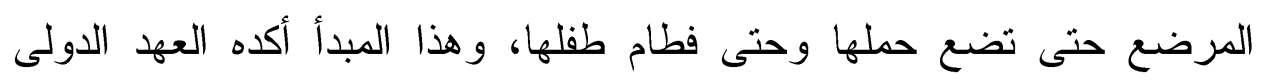

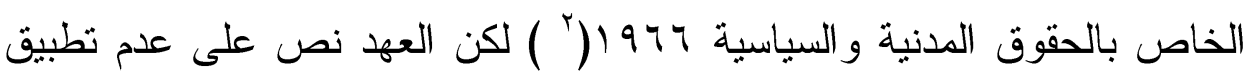

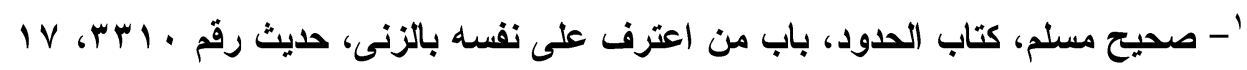

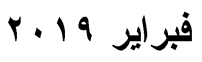

http://www.hadithportal.com/index.php?show=hadith\&h_id=rr1 \& \&u $i d=. \&$ sharh $=1 \ldots$. \&book $=r \mid$ \&bab_id $=V \leqslant r$

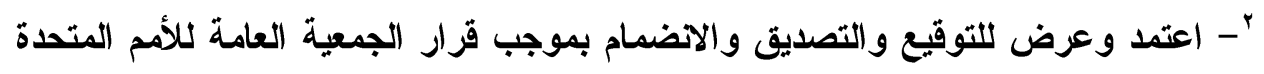

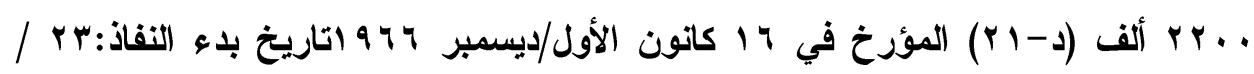
مارس/9V7 19، وفقا لأحكام المادة 9 ؛. 
(د.نعيمة فرج عبدالنبى) ساعات الرضاعة الطبيعية للام العاملة فى قانون العمل البحرينى

عقوبة الاعدام على المرأة الحامل فقط حتى تضع حملها وترك تطبيق عقوبة إلاعدام بعد الولادة لقوانين الدول الداخلية، ولم ينص على ضرورة إرضاع الطفل. - الم.

فهنا نجد عظمة ورحمة الأسلام وحرصه على الطفل. وهذا ما أخذت به مملكة

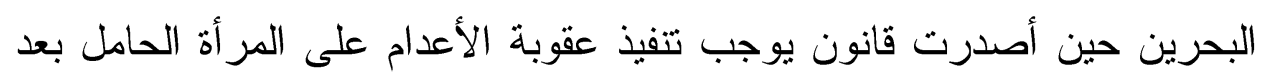

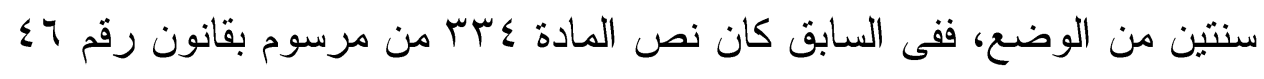

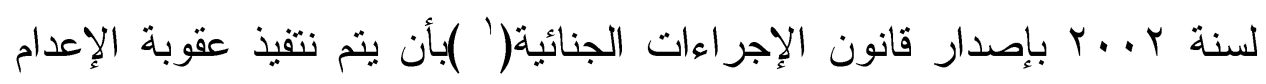

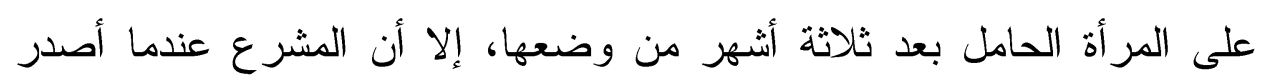

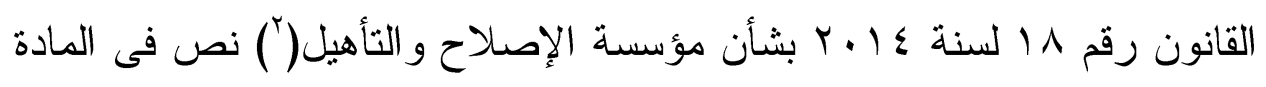
ד7 من الفصل الثاني من القانون والخاص بتتفيذ عقوبة الإعدام على أنه "إذا كانت المر أة المحكوم عليها بالإعدام حبلى يوقف تنفيذ الحكم إلى ما بعد سنتين

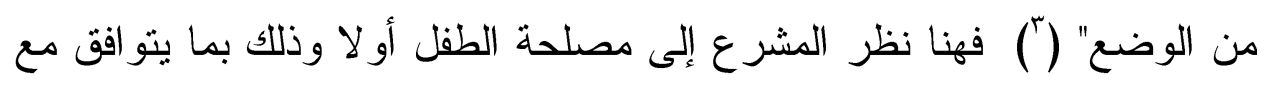
الثريعة الإسلامية ومع المادة الثانية من دستور المملكة التى تتص على على أن" دين الثن

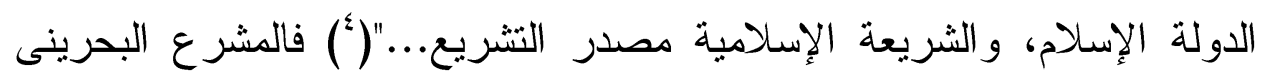

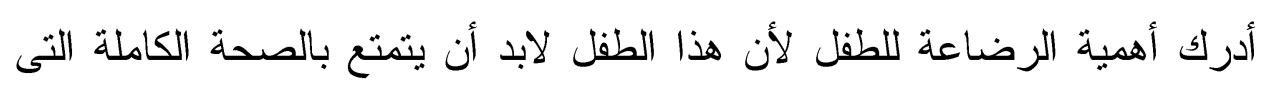

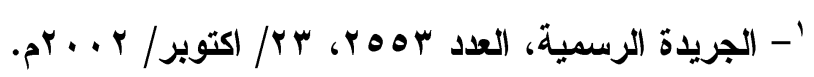

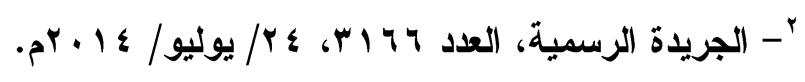

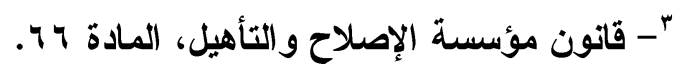

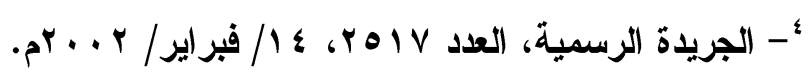


(د.نعيمة فرج عبالنبى) ساعات الرضاعة الطبيعية للام العاملة فى قانون العمل البحرينى

يحصل عليها من حليب أمه، لما في ذلك من تقدير شرعي وبعد إنساني، الغاية

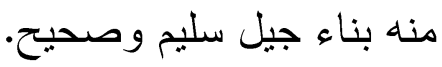

فمن خلال ما تقدم فإن الحق فى الرضاعة الطبيعية فى الشريعة الاسلامية يبين

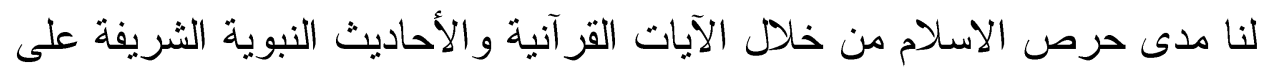
الرضاعة الطبيعية وعلى مصلحة البشر في ترسيخ المفاهيم الإنسانية وبناء جيل

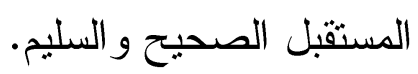

\section{المطب الثاني}

\section{الحق فى الرضاعة الطيعية فى قانون العمل البحرينى}

يدرك المشرع البحرينى دور المرأة فى المجتمع ويدرك مدى تأثيرها فى الأسرة

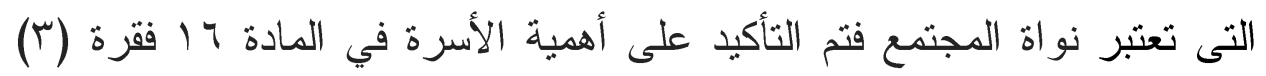

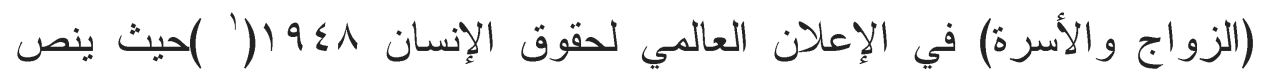
على أن الأسرة هي الوحدة الطبيعية والأساسية للمجتمع، ولها الحق فى الحماية الإنسية

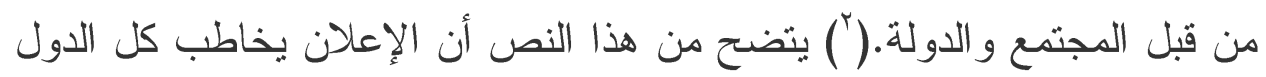

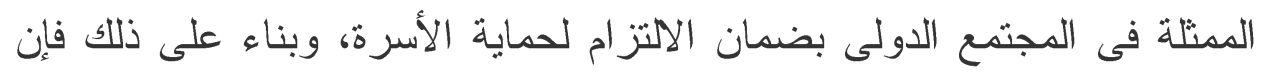

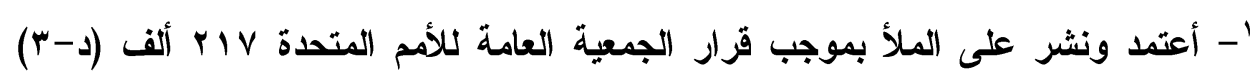

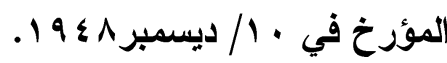

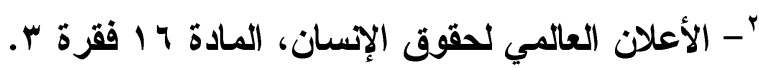


(د.نعيمة فرج عبالنبى) ساعات الرضاعة الطبيعية للام العاملة فى قانون العمل البحرينى

مملكة البحرين أعلنت التزامها ببنود الإعلان العالمي لحقوق الإنسان فى نطاق (') (حدود) عدم تعارضها مع الشريعة الإسلامية. (')

و هذا ما أكده دستور مملكة البحرين الصادر في ب ...r(†) فى المادة الخامسة فقرة (أ) بأن " الأسرة أساس المجتمع قو امها الدين والأخلاق وحب الوطن، يحفظ

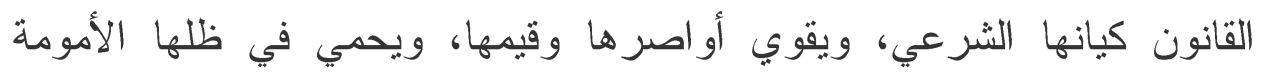
و الطفولة، ويرعي النشء،..."(") وكذالك تم التأكيد على أهمية ما تمثله الأسرة للمجتمع فى البند السادس من الفصل الأول من ميثاق العمل الوطنى لدولة

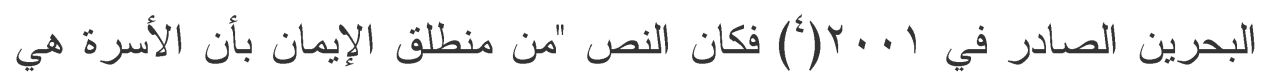
اللبنة الأساسية للمجتمع، وبصلاحها تقوى أواصره وتعلو قيم الدين والأخلاق

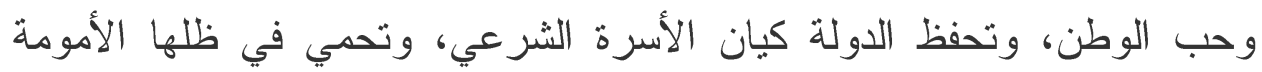

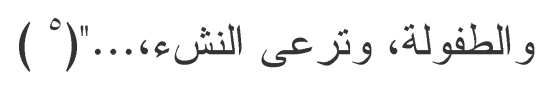

من خلال ما تقدم نلاحظ أنه تم التأكيد على أهمبة الأسرة سواء على المستوى الدولي أو الوطنى وتم التأكيد على أهمية حماية الأسرة من المجتمع و الدولة.

'- مريم بنت حسن آل خليفة وعبدالكريم علوان، ملتقى البحرين في حقوق الإسان، الطبعة

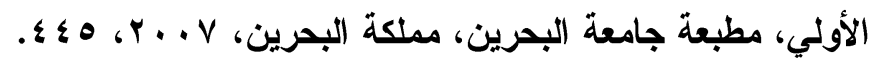

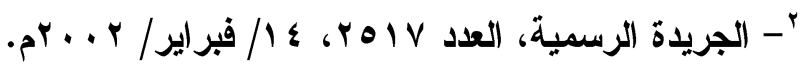

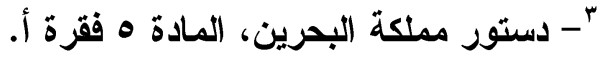

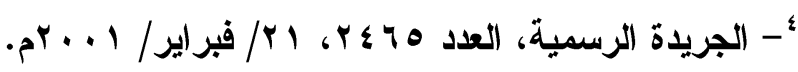
مْ - ميثاق العمل الوطنى لاولة البحرين، البند السادس. 
(د.نعيمة فرج عبالنبى) ساعات الرضاعة الطبيعية للام العاملة فى قانون العمل البحرينى

وتجدر الملاحظة هنا أن الأعلان العالمي لحقوق الإنسان جاء تأكيده على أهمبة

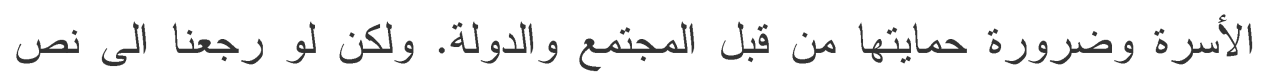

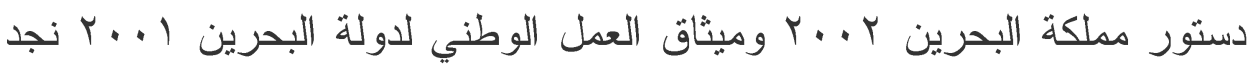

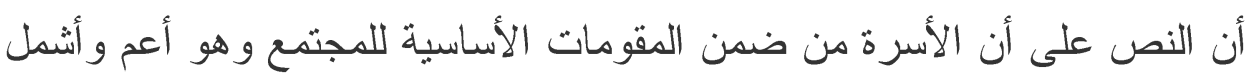

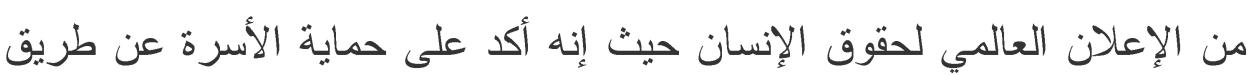

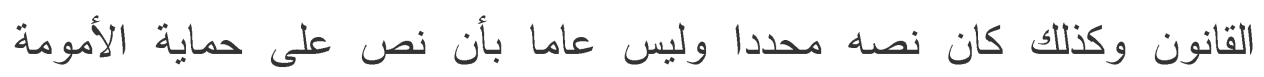

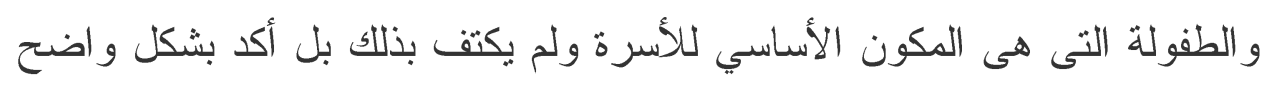
و صريح على حماية ورعاية جيل المستقبل وهم النشء.

أكلت هذه الدراسة على أهمية حماية الأسرة والمر أة فهذه الحماية لا تكون إلا عن طريق إيجاد (تشريع) قانون يمنح للمرآة الحق فى التمتع بحقها فى العمل العله

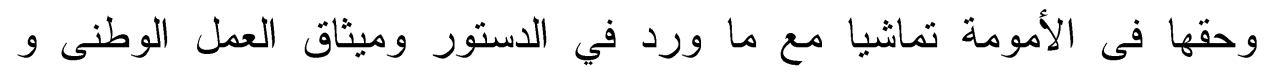

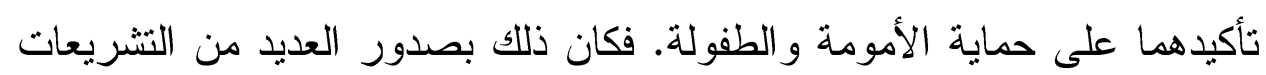

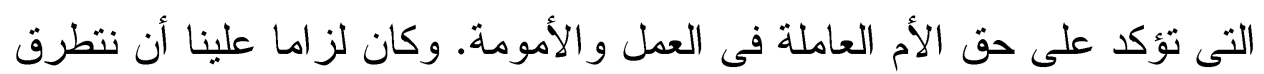

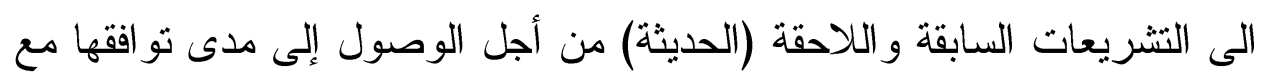
الشريعة الاسلامية و مع حق الأم العاملة فى تمتعها بحق العمل و الأمومة.

ومن ثم سنتطرق بالشرح و التحليل لثلاثة تشريعات منحت للأم العاملة الحق فى الرضاعة الطبيعية وذلك فى ثلاث فقرات على النحو التالى: 
(د.نعيمة فرج عبدالنبى) ساعات الرضاعة الطبيعية للام العاملة فى قانون العمل البحرينى

\section{الفرع الأول}

\section{الحقى فى الرضاعة الطيعية في ظل قاتون العمل فى القطاع الأهلى رقم بr I}

\section{لسنة 19V7}

تم تأكيد الحق فى الرضاعة الطبيعية للأم العاملة بنص المادة با من قانون

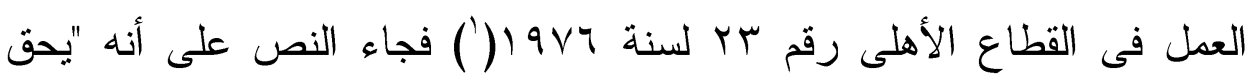

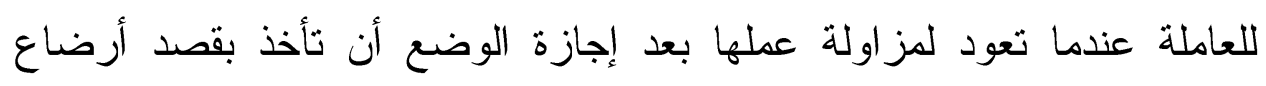

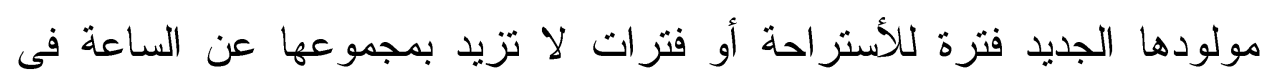
اليوم الواحد وذلك علاوة على فترات الر احة الممنوحة لجميع العمال"، فيتضح لنا

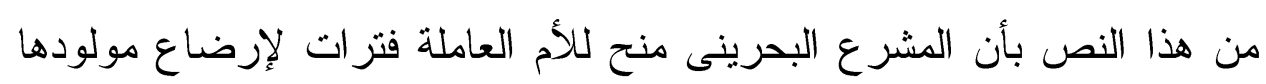

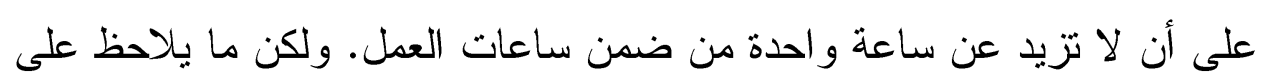

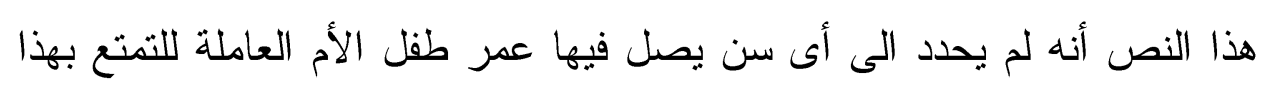
الحق ولذلك أدرك المشرع البحرينى عدم تحديد فترات الرضاعة الطبيعية

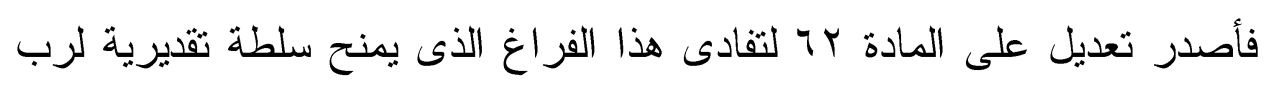
العمل، و هذا هو موضوع الفقرة التالية.

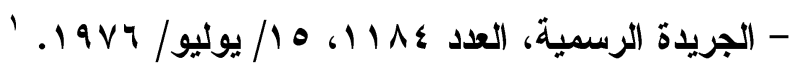


(د.نعيمة فرج عبدالنبى) ساعات الرضاعة الطبيعية للام العاملة فى قانون العمل البحرينى

\section{الفرع الثاني}

\section{الحق في الرضاعة الطيعية في ظل القانون رقم ع السنة ب 99 التعديل}

\section{قانون العقل في القطاع الأهلى}

لقد استدرك المشرع البحرينى عدم تحديد الى اى مرحلة من عمر الطفل تتمتع

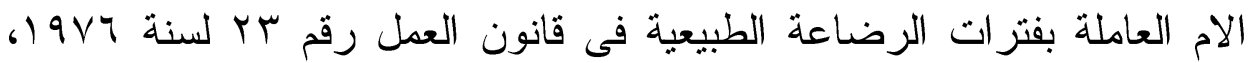
فأصدر المرسوم بقانون رقم ع السنة r999(') بتعديل المادة rآ من قانون

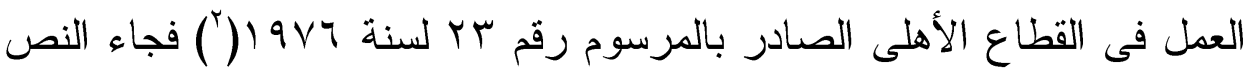
كالتالي: "فى خلال السنتين التاليتين لتاريخ الوضع يحق للعاملة عند عودتها لمزاولة عملها بعد اجازة الوضع أن تأخذ بقصد إرضاع مولودها الجديد فترة للإستراحة أو فترتين لا تزيد بمجموعها على الساعة فى اليوم الواحد وذلك علاوة على فترات الراحة الممنوحة لجميع العمال". ثم جاءت الفقرة الثانية من نفس المادة "ولصاحب العمل بعد كل ستة شهور من تاريخ الوضع أن يطلب من العاملة تقديم شهادة طبية معتمدة من المركز الصحى التابع له محل إقامتها يبين

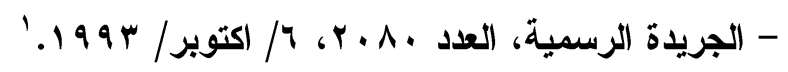

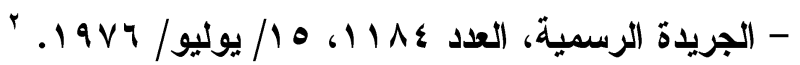


(د.نعيمة فرج عبالنبى) ساعات الرضاعة الطبيعية للام العاملة فى قانون العمل البحرينى

بها استمر ارها فى ارضاع مولودها فإذا لم تقدمها خلال شهرين من تاريخ طلبها

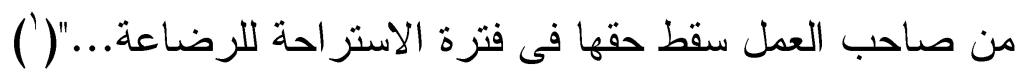

هذا المرسوم الذى عدل المادة بr من قانون القطاع الأهلى أدرك أهمية الرضاعة الطبيعية للأم و الطفل و المجتمع وذلك بتحديده مدة الرضاعة الطبيعية للأم العاملة لمدة سنتين فهذا يعتبر استجابة لما ورد في القرآن الكريم "و الو الدات يرضعن أولادهن حولين كاملين..."( (ب كذلك هذا التعديل يؤكد على دستورية

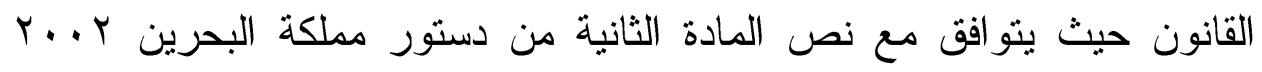
الذى نص على أن "دين الدولة الاسلام، والثريعة الإسلامية مصدر رئيسي مليدي للتشريع".(") و أهم إضافة أضافها هذا المرسوم أنه لم بعط لصاحب العمل السلطة التقديرية فى تحديد منى تتنهى مدة الرضاعة للأم العاملة الممنوحة لها بنص

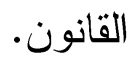

الا أنه نظرا ل لهحاولة زيادة حقوق المرأة العاملة فى القطاع الخاص تم إضافة مز ايا جديدة للمر أة ونت تخفيض ساعات الرضاعة الطبيعية وذلك بصدور قانون جديد سيكون موضوع الفقرة التالية.

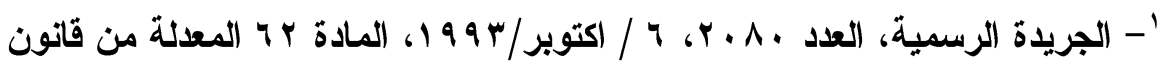

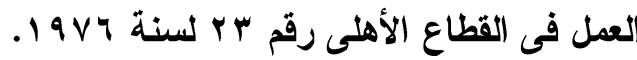

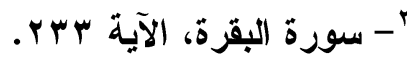

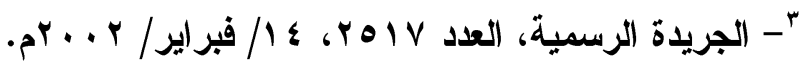


(د.نعيمة فرج عبدالنبى) ساعات الرضاعة الطبيعية للام العاملة فى قانون العمل البحرينى

\section{الفرع الثالث}

الحقى فى الرضاعة الطيعية فى ظل قانون العمل فى القطاع الأهلي رقم بَس

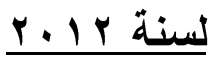

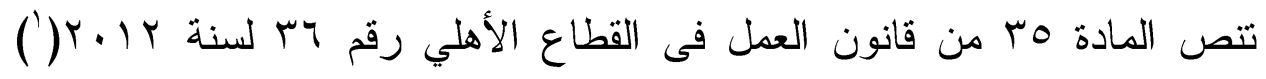

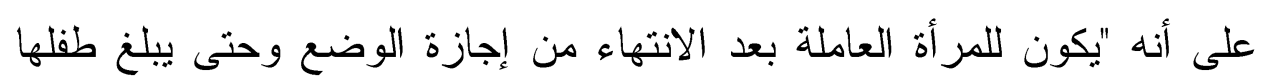
ستة أ شهر من العمر فترتا رعاية لرضاعة طفلها على ألا تقل مدة كل منهما

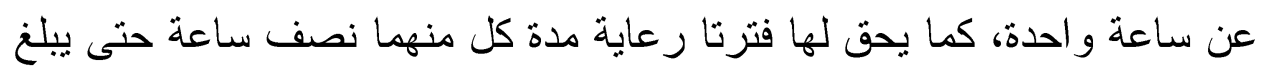
طفلها عامه الأول، وللعاملة الدق في ضم هاتين الفترتين وتحسب هاتان الفترتان

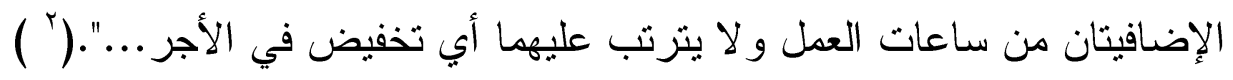
نلاحظ من خلال هذا النص بان القانون الجديد تميز بميزة مهمة جدا وهى أنه أطال ساعات الرضاعة لساعتنن للأم العاملة كحق من حقوقها، وهذا يعتبر تطوراً كبيراً عن القوانين السابق ذكرها(")، وحدد كذللك مدة التمتع بهاتين الساعتين حتى يبلغ طفلها ستة أشهر، و هذا يعتبر ضمانة وحماية أكثر للطفل

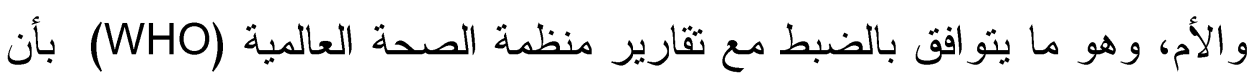

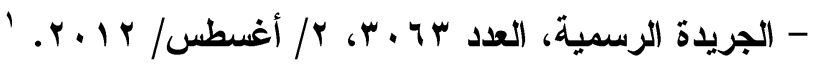

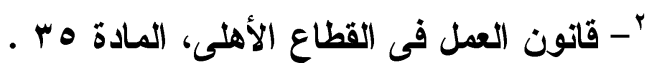

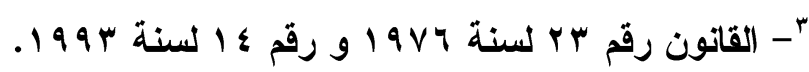


(د.نعيمة فرج عبدالنبى) ساعات الرضاعة الطبيعية للام العاملة فى قانون العمل البحرينى

رضاعة الطفل رضاعة مستمرة لمدة ستة أشهر توفر له و لأمه حماية أفضل على

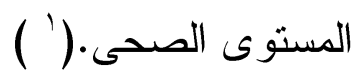

كما اعتبر ساعات الرضاعة الطبيعية من ضمن ساعات العمل ولا يترتب عليها تخفيض فى مرتب الأم العاملة، مع العلم إن القوانين السابق ذكرها أكدت على ذلك، و هذا يعتبر تشجيعا للأم العاملة على الرضاعة الطبيعية وكذلك المحافظة على أجرها، وحماية لصحة الأم و الطفل، فساعات الرضاعة الطبيعية التى تعتبر من ضمن ساعات العمل المدفوعة الأجر لها دور كبيز حيث تزيل الاهتمامات المالية المتعلقة بالعمل، فهى ضرورية لحماية الأمومة ومنحها للأم العاملة بدلاً من الاضطرار بسبب الضرورة الاقتصادية إلى الانخر اط في العمل و إهمال

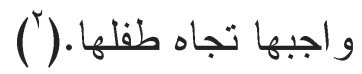

ولكن برغم هذا التطور الذى يحمله هذا القانون له العديد من السلبيات نتعرض لها بالثرح على النحو الآتي: تحمل المادة هب من القانون عدة سلبيات تتعلق بساعات الرضاعة الطبيعية: '- منظمة الصحة العالمية، الأسبوع العالمي للرضاعة الطبيعية، مركز وسائل الاعلام

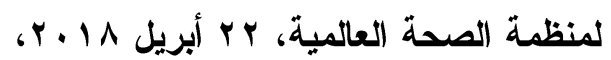
http://www.who.int/mediacentre/events/ץ. $17 /$ world-breastfeeding/week/ar

Daniel Cere, 'Human Rights and the Family' ( $r \ldots q) r r(1)-^{r}$ Academic Questions ir, $v \varepsilon$. 
(د.نعيمة فرج عبالنبى) ساعات الرضاعة الطبيعية للام العاملة فى قانون العمل البحرينى

1- من أهم السلبيات أنه قلص ساعات الرضاعة الطبيعية الى ساعة واحدة، بعد أن يصل عمر الطفل ستة أثهر و حتى يبلغ سنة من عمره.

r- ولم يقف المشرع الى هذا الحد بل قلص مدة تمتع الأم العاملة بساعات الرضاعة الطبيعية إلى حين وصول طفلها عامه الأول فقط وبعد ذلك ليس لها الدق فى أكمال تغذية طفلها. و هذا بالطبع مخالف لما ورد فى كتاب اله بأن حدد

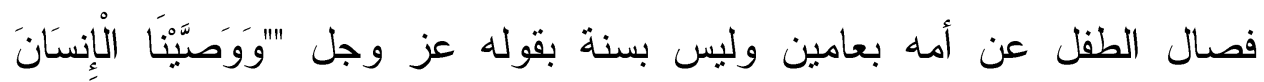

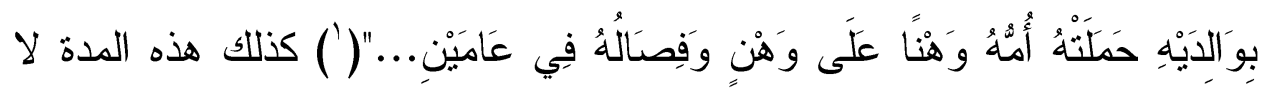
توفر الحماية الكاملة لصحة الطفل و الأم. r- كذلك ترك لرب العمل تحديد فتر ات الرضاعة الطبيعية وفقا لظروف العاملة ومصلحة العمل، كيف يترك أمر كهذا لرب العمل الذى ينظر الى مصلحة العمل بغض النظر عن أى شئ آخر فهدفه الكسب وأى شئ يخالف ذلك لا يهمه، أين مصلحة الطفل التى من المفترض أن ينظر لها فى المقام الأول، خاصة إذا رجعت العاملة إلى العمل بعد إجازة الوضع مباشرة فعمر الطفل هنا ثلاثة أشهر فكيف يحدد رب العمل منى يحتاج الطفل إلى الغذاء فهذا خرق لحق الطفل فى الغذاء، ومخالف لإتفاقية حقوق الطفل(') و التى تعتبر مملكة البحرين طرفا لقاء

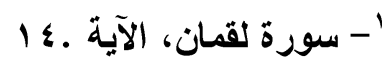
هـ- اعتدت وعرضت للتوقيع والتصديق والأضمام بموجب قرار الجمعية العامة رقم

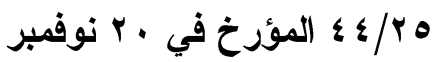


(د.نعيمة فرج عبالنبى) ساعات الرضاعة الطبيعية للام العاملة فى قانون العمل البحرينى

فيها(') حيث تتص الفقزة الأولى من المادة الثالثة من الاتفاقية على أنه "في جميع الإجراءات التي تتعلق بالأطفال، سواء قامت بها مؤسسات الرهات الرعاية الاجتماعية العامة أو الخاصة، أو المحاكم أو السلطات الإدارية أو الهيئات التشريعية، يولي الاعتبار الأول لمصالح الطفل الفضلى".

ويأتى المشرع بعد ما نص على أن "يحدد صاحب العمل موعد فنزة

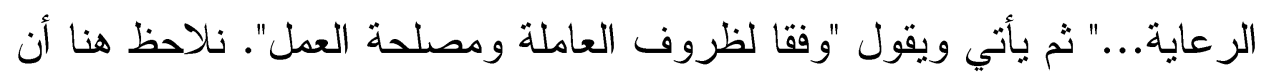

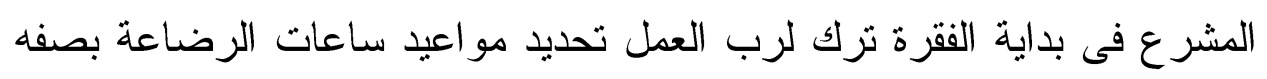
مطلقة، ثم يأتى فى نفس الفقرة ويقبدها وفقا لظروف العاملة ومصلحة العمل فهنا

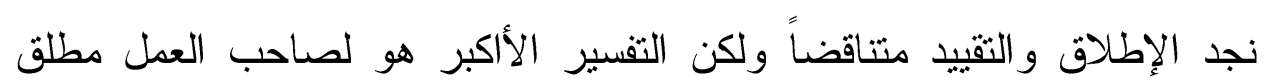
الصلاحية فى تحديد موعد فترة الرعاية وهنا له كل الصلاحية فى ذلك وفقا للقانون.

ع- أهم ما يعاب على هذا القانون أنه حذف الفقرة الثانية من المرسوم بقانون

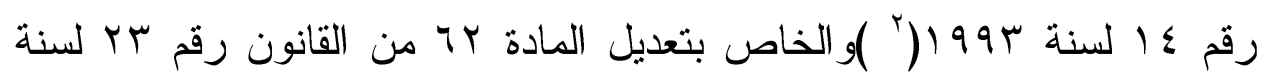
19V7 ، و والتى كان نصها " ولصاحب العمل بعد كل ستة أشهر من تاريخ الوضع ان يطلب من العاملة تقديم شهادة طبية معتمدة من المركز الصحى التابع

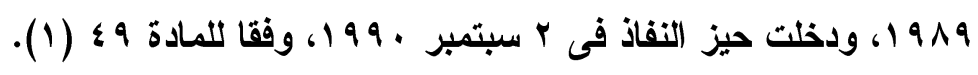

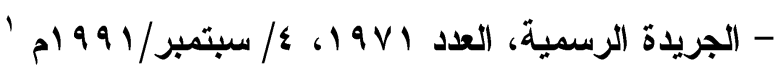

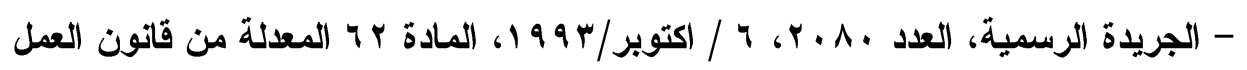

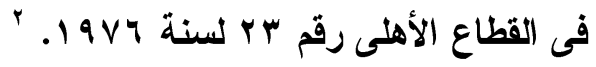


(د.نعيمة فرج عبالنبى) ساعات الرضاعة الطبيعية للام العاملة فى قانون العمل البحرينى

له محل إقامتها يبين بها استمر ارها فى إ رضاع مولودها فإذا لم تقدمها خلال شهرين من تاريخ طلبها من صاحب العمل سقط حقها فى فترة الاستراحة

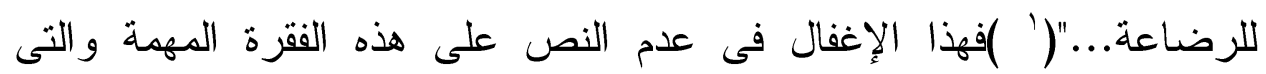

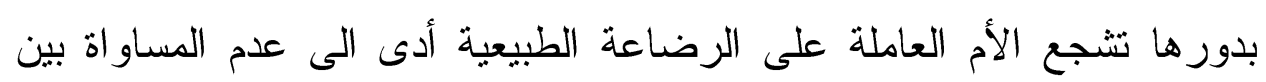

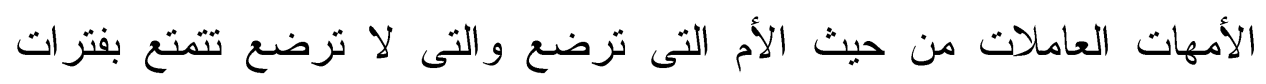

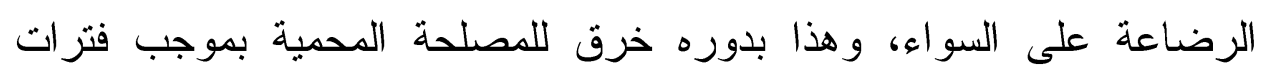
الر احة و التى هى مصلحة الأم و الطفل التى نص عليها القانون.

\section{المطلب الثالث}

\section{ساعات الرضاعة الطيعية بين النظرية والتطيق}

من خلال العرض الذى تم بخصوص حق الرضاعة الطبيعية فى التشريع

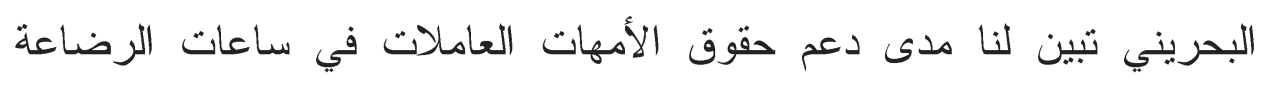
الطبيعية، والهدف من هذه الدراسة هو قياس مدى التمتع الفعلي بالحقوق التي لئي

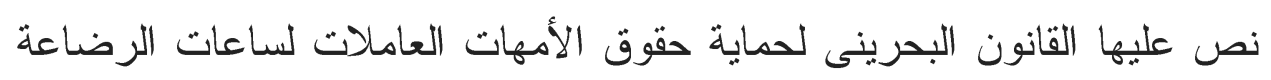

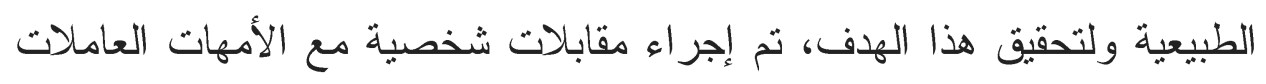

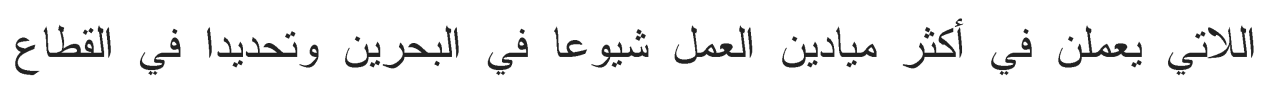

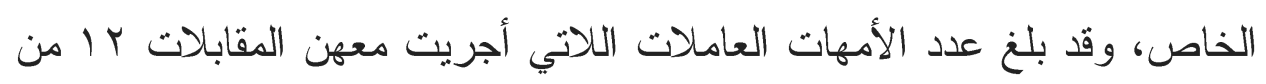

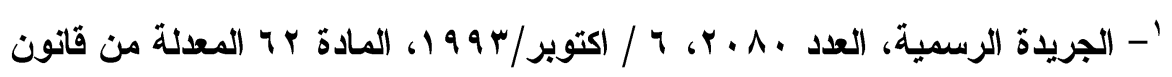

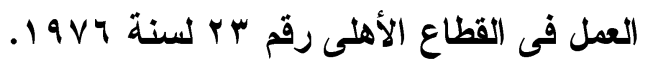


(د.نعيمة فرج عبالنبى) ساعات الرضاعة الطبيعية للام العاملة فى قانون العمل البحرينى

الأمهات العاملات، وصنفن في ثلاث فئات، يتألف كل منهن من ع أمهات . وتثمل كل فئة نوع محدد من الوظائف: التعليم، و البنوك، و الثركات، و استبعدت النساء العازبات و النساء المتزوجات اللواتي لم يكن لايهن أطفال، وكان ذلك شرطا أساسيا لاجر اء المقابلات لأن هذا البحث يتعلق بتجربة الأمهات العاملات،

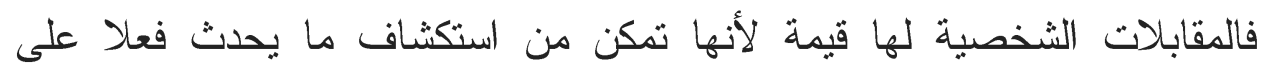

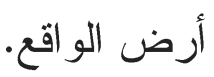

وقبل عرض نتائج المقابلات الشخصية نعرض فى الفقرة الأولى شكل المقابلات الثخصية مع الأمهات العاملات وفى الفقزة الثانية نتائج هذه المقابلات

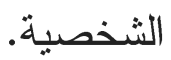

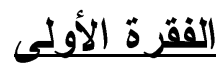

\section{شكل المقابلات الثخصية}

وكانت المقابلات شبه منظمة، وكل مقابلة تمت بقائمة موحدة من الأسئلة معظمها مفتوحة (open-ended questions) وهى على عكس الاستبيان حيث تم إعطاء المشاركات الفرصة للتعبير عن وجهات نظرهن بطريقة مفتوحة.(') كما أتيحت حرية كبيرة في التركيز و التوسع في القضايا ذات الأهمية بطريقة بمكن

Uwe Flick, An Introduction to Qualitative Research (SAGE -'

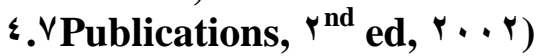


(د.نعيمة فرج عبدالنبى) ساعات الرضاعة الطبيعية للام العاملة فى قانون العمل البحرينى

التعبير عنها في شكل إجابات وبالتالي تصبح متاحة للتفسير".(') و المعلومات المستمدة من المقابلات الشخصية توفر فهما غنيا ومتعمقا للمشكلة قبد

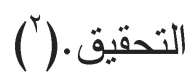

المقابلة الشخصية تعتبر الأداة الرئيسية المستخدمة للوصول إلى الحقائق في نهاية المطاف.(r )فهي تمكن الباحثين من الوصول إلى ممارسات الفرد ومعارفه، أي "العمليات الغنية و المعقدة التي تشكل تجربة حياة الفرد".(") وكانت المقابلات مع الأمهات العاملات نهجا مقارنا لمقارنة نظرية حقوق الأمهات العاملات وممارسة تلك الحقوق في الظروف الحقيقية للحياة اليومية المتعددة الأوجه للعمل والأمومة، كما هي ممثلة في ردود النساء اللاتي أجريت معهن المقابلات، وكما لاحظ مارشال وروسمان "لا يمكن للمرء أن يفهم الأعمال البشرية دون فهم المعنى الذي يعزوه المشاركون لتلاك الأعمال أفكارهم ومشاعرهم ومعتقداتهم وقيمهر

Uwe Flick, An Introduction to Qualitative Research (SAGE -' \&.^ Publications, ${ }^{\text {nd }}$ ed,, r.. r)

Beverley Hancock, An Introduction to Qualitative Research (Trent Focus Group, 1 9 १) १; see also Terry Hutchinson, Researching and Writing in Law ( $\boldsymbol{r}^{\mathrm{rd}}$ ed, law Book Co of Australasia, $\left.\left.r \cdot 1 \cdot\right)^{\prime}\right) \cdot v$. Robert E Stake, The Art of Case Study Research (SAGE Publications, 1990) 1 .

Cassandra E Sharp, Becoming a Lawyer: the Transformation of -" Student Identity Through Stories (PhD Thesis, University of Wollongong, $r \ldots$. $) \vee r$. 
(د.نعيمة فرج عبدالنبى) ساعات الرضاعة الطبيعية للام العاملة فى قانون العمل البحرينى

وعوالمهم الافتراضية، لذلك يحتاج الباحث إلى فهم وجهات النظر الأعمق التي

يتم الثقاطها من خلال التفاعل وجها لوجه".(')

وفي هذا السياق، تعتبر المعلومات من هذا النوع ذات قيمة خاصة لأن هذه الدراسة هي من الدراسات القانونية القليلة من حيث النوع في هذا المجال في القانون البحرينى، ومما يسهل عمق و اتساع الأفكار أيضا حالة عدم الكثف عن هن هوية من أجريت معها المقابلة وكانت النساء العاملات اللواتي تمت مقابلتهن يتمتعن بالحرية في وصف الو اقع كما تعرضن له أو (تعاملن معه).

\section{الكقرة الثانبة}

\section{نتائج المقابلات الثخصبة}

من خلال المقابلات الشخصية التى تمت مع الامهات العاملات تبين أن أغلب

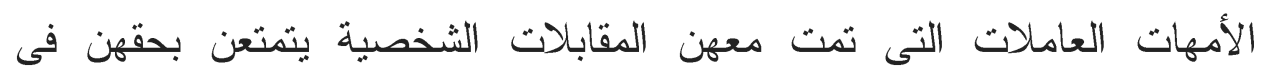

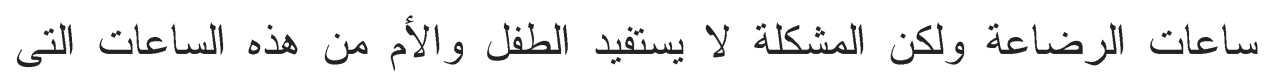

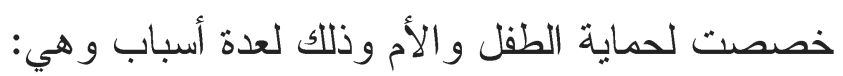

1- صاحب العمل يمنح فترات الرضاعة قبل نهاية الدوام، فهنا الطفل ينتظر

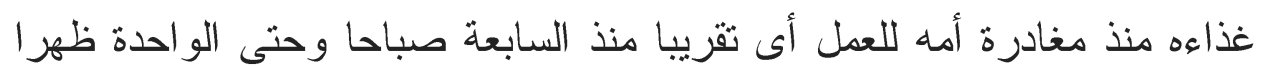
.Qualitative Research $\left({ }^{\mathrm{rd}} \mathrm{ed}, 1999\right)$ o $\mathrm{V}$ 
(د.نعيمة فرج عبالنبى) ساعات الرضاعة الطبيعية للام العاملة فى قانون العمل البحرينى

لمدة 7 أثنهر وبعد ذلك تظل الأم فى العمل من السابعة صباحا وحتى الثانية ظهر ا حسب طبيعة العمل ولمدة 1 أشهر، و هذا يؤثر على الطفل وعلى نسبة حليب الأم حيث تقل نسبة الحليب لبقاء حليب الأم فترة طويلة بدون رضاعة.

ץ- تقضى أغلب الأمهات فترات الرضاعة فى الطريق حتى تصل بيتها نظرا لبعد منزلها عن مكان العمل، فوجدت من تقضى ربع ساعة وهى الأقل ومنهن نصف ساعة و هناك من تقضى ساعة كاملة حسب الازدحام في الطريق.

r-أغلب الأمهات العاملات أكدن بأن خلال تواجدهن فى العمل فإن أطفالهن يتغذون على الحليب الصناعي و هذا بالطبع له تأثير على صحة الطفل حيث إن أغلب الأطفال يعزفون عن الحليب الطبيعى لأن الحليب الصناعى يحتوي نسبة عالية من السكر ولذلك فإن الطفل يفضله.

ع- تعديل القانون أثر فى صحة أطفال الأمهات العاملات حيث إن القانون السابق(') يعطى للأم العاملة ساعة رضاعة لمدة سنتين، أما القانون الجديد(') فقد خف هذه المدة لسنة واحدة فقط تبين ذلك من خلال المقابلات التي أجريت مع الأمهات العاملات وكانت واحدة منهن قد أكدت بأنه من خلال خبرتها فى هي الوظيفة التي استمرت لمدة ^ سنوات رزقت بطفلين الأول كان في فترة سريان القانون القديم حيث استمرت فى إرضاع طفلها لمدة سنتين كاملتين والنتيجة أن

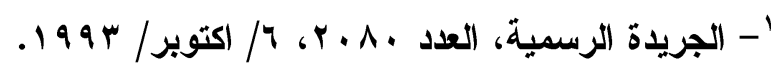

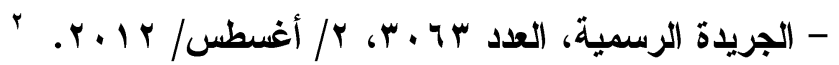


(د.نعيمة فرج عبدالنبى) ساعات الرضاعة الطبيعة للام العاملة فى قانون العمل البحرينى

طفاها صحته ممتازة أما طفلها الثاني فقد أنجبته بعد نفاذ القانون الجديد فتم إرضاعه لمدة سنة واحدة فقط وقد أكدت بأن صحته تختلف تماما على شقيقه.

0- أغلب أماكن العمل لا توجد بها دار حضانة لأطفال الأمهات العاملات وهناك بعض جهات العمل بصل عدد النساء العاملات إلى 10 عاملة ولا توجد دار رعاية ولكن خلال المقابلات الثخصية وجدت أن احدى الددارس الخاصة أنشأت دار حضانة لأطفال الأم العاملة على أفضل مستوى والأم العاملة تساهم بدفع ونات

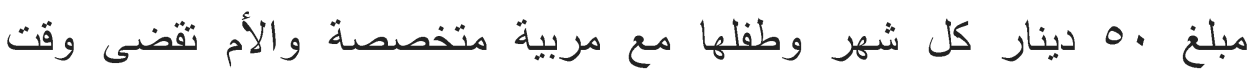

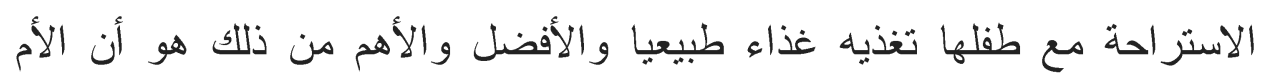
تتمتع بفترات الرضاعة الطبيعية الممنوحة لها بناء على القانون وهذا شئ جدا مهم يضمن استمرار الأم فى إرضاع طفلها بعد إجازة الوضع وهذا يوفر حماية لها ولطفلها وفائدة كبرى لجهة العمل حيث إن انتاجية الأم ستزيد بوجود طفلها

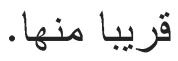


(د.نعيمة فرج عبدالنبى) ساعات الرضاعة الطبيعة للام العاملة فى قانون العمل البحرينى

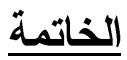

وفى الختام بعد أن تعرضنا لأهمية الرضاعة الطبيعية للأم و الطفل والمجتمع،

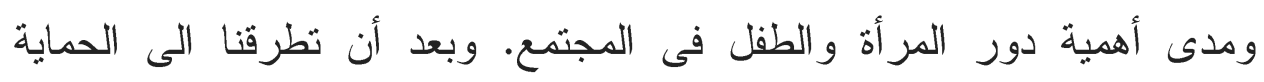

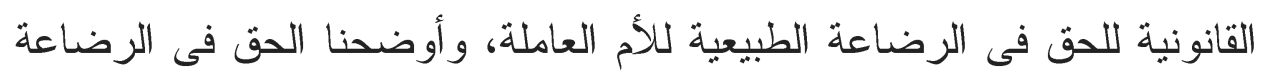

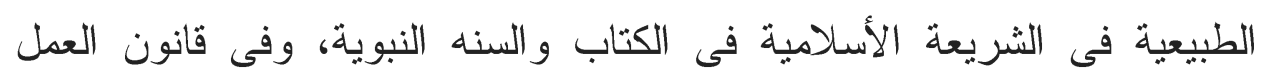

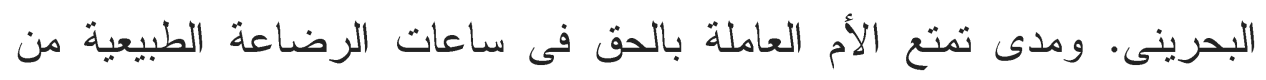
الناحية العملية وذلك عن طريق المقابلات الشخصية التى تمت مع الأم العاملة فى القطاع الخاص اتضح لنا العديد من النتائج و التوصيات.

من خلال نتائج المقابلات الثخصية التى تمت مع الأم العاملة يتضح أن

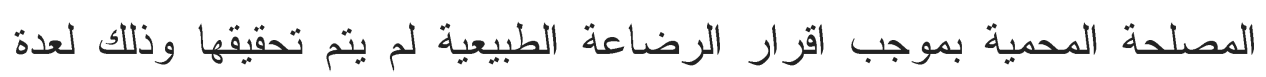

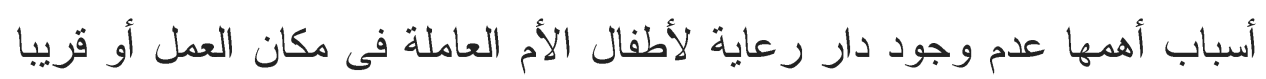
منه الأمر الذي أدى الى خرق حق الأم والطفل في الحماية الصحية الممنوحة

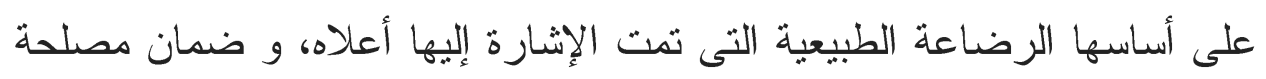
رب العمل و الوفاء بالالتزامات الدولية التى صادقت عليها مملكة البحرين المشاركة في تحمل نفقات ساعات الرضاعة وسنتطرق بالشر ح لهذه النقاط تباعا: 
(د.نعيمة فرج عبالنبى) ساعات الرضاعة الطبيعية للام العاملة فى قانون العمل البحرينى

1- بخصوص خرق حق الأم والطفل بعدم حصول الطفل على الرضاعة

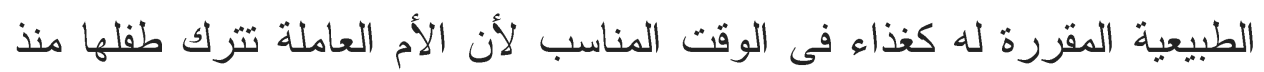

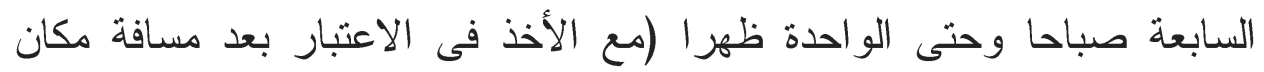
العمل عن مكان سكن الأم العاملة فقد يأخذ ساعة كاملة حتى تصل محل سكنها)

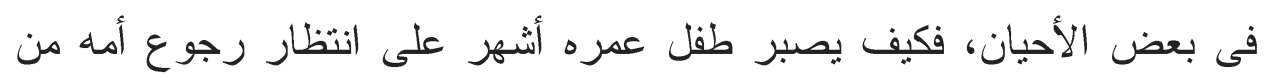

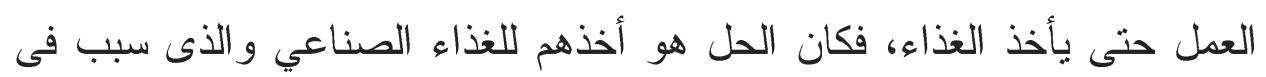
عزوف كثبر من الأطفال عن الغذاء الطبيعى، والذى بدوره يؤثر على صحة الأم

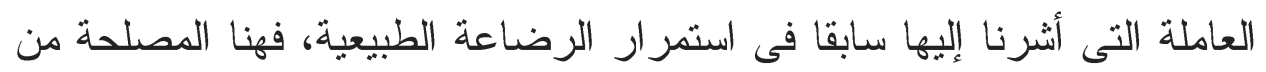
ساعات الرضاعة الطبيعية لم يتم الوصول إليها بسبب عدم وجود حضانة في تلي مكان عمل الأم أو قريبة منه.

ץ- ضمان مصلحة رب العمل، ويتمثل ذلك فى وجود دار رعاية لطفل الأم العاملة فى مكان العمل حتى يضمن رب العمل مصلحة العمل والمتمثلة بأن تقضي الأم العاملة فترات الرضاعة فى مكان العمل وكذلك ينم ترتيب أوقات

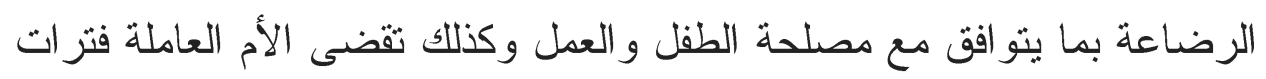

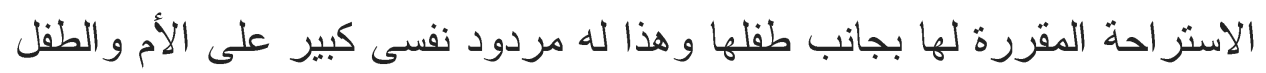

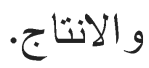

r- نجد ان الاتفاقيات الدولية نصت على وجود دار لحضانة أطفال الأم العاملة لتمكينها من التمتع بحقها فى العمل وحقها فى الأمومة ومن هذه الاتفاقيات، لانهات 
(د.نعيمة فرج عبالنبى) ساعات الرضاعة الطبيعية للام العاملة فى قانون العمل البحرينى

اتفاقية القضاء على جميع أثنكال التمييز ضد المرأة 9V9 ام (CEDAW)(')

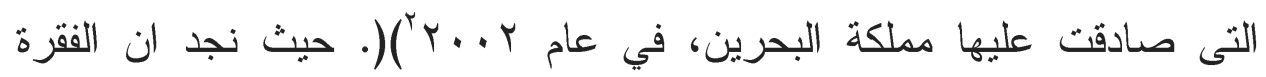

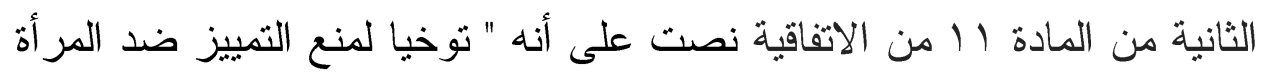
بسبب الزواج أو الأمومة، ضمانا لحقها الفعلي في العمل، تتخذ الدول الأطراف التدابير المناسبة" ومن هذه التدابير هو ما نصت عليه البند (ج) من المادة 11 فقرة r: "لتثجيع توفير الخدمات الاجنماعية المساندة اللازمة لتمكين الو الدين من الجمع بين الالتزامات العائلية وبين مسؤوليات العمل والمشاركة في الحياة العامة، ولا سيما عن طريق تشجيع إنثاء وتتمية شبكة من مرافق رعاية

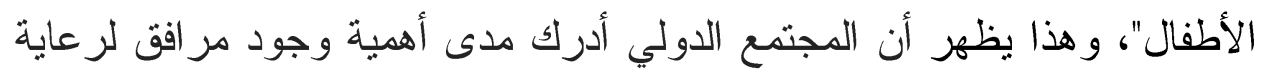
الأطفال حتى تتككن المرأة العاملة من التوفيق بين التزاماتها العائلية وواجباتها

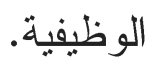

ع - المشاركة في تحمل نفقات ساعات الرضاعة الطبيعية، فهذا كذلك من ضمن العوامل التى أدت إلى عدم فاعلية ساعات الرضاعة الطبيعية كما كان الدقصود من النص عليها، فمن غير المنطقى أن يدفع صاحب العمل أقساط التأمين الاجتماعى للعاملة ( بنسبة ؛ (\% من مرتب العاملة) ثم يتحمل لوحده نفقات ساعات الرضاعة الطبيعية كاملة، فكما نعلم بأن ساعات الرضاعة الطبيعية تعتبر

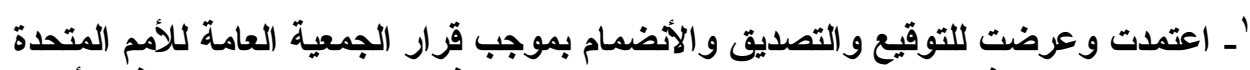

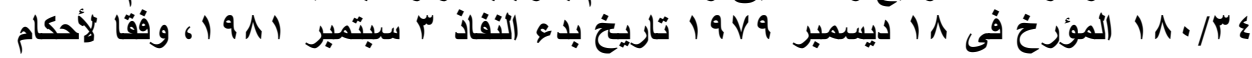

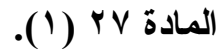

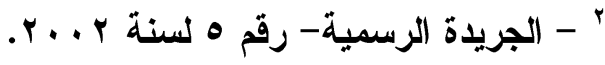


(د.نعيمة فرج عبالنبى) ساعات الرضاعة الطبيعية للام العاملة فى قانون العمل البحرينى

من ضمن ساعات العمل فهذا سيشكل عجز فى الانتاج لصاحب العمل الذى

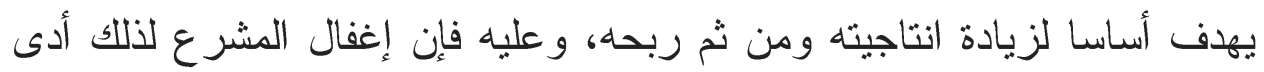
إلى عزوف رجال الأعمال عن توظيف النساء(') و هذا بدوره له تأثير كبير على المستوى الاقتصادى و الاجتماعي للدولة.

و عليه فمن المستحسن أن يسلك المشرع البحريني ما سلكه المشرع الدولي عندما نص على حماية المرأة عن طريق اتاحة الفرصة لها للتمتع بحقها فى العمل و الأمومة مع فاعلية العمل ونجاحه وذلك بأن نص على حق المرأة العاملة في الحماية الخاصة خلال الحمل وبعده وذلك فى الفقزة الثانية من المادة العاشرة من

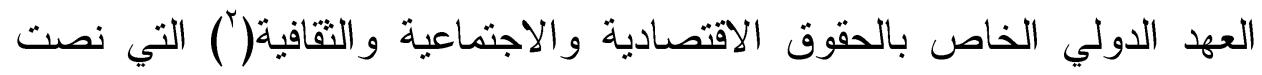
على "وجوب توفير حماية خاصة للأمهات خلال فترة معقولة قبل الوضع وبعده، وينبغي منح الأمهات العاملات، أثناء الفترة الدذكورة، إجازة مأجورة أو إجازة مصحوبة باستحقاقات ضمان إجتماعي كافية"(").

'- عدنان خليل التلاوي، القانون الدولي للعمل"ثشروحات لمنظمة العمل الدولية و التشريع

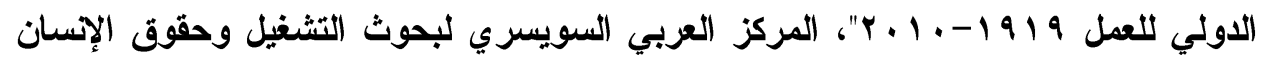

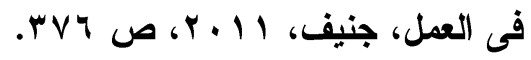
r- أعتد وعرض للتوقيع و التصديق و الالضمام بموجب قرار الجمعية العامة للأمم المتحدة STr..

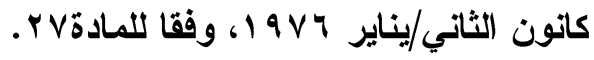

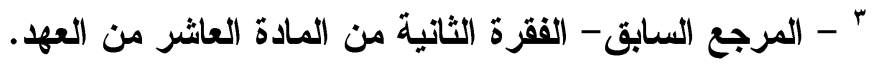


(د.نعيمة فرج عبدالنبى) ساعات الرضاعة الطبيعية للام العاملة فى قانون العمل البحرينى

وهذا النص جاء من أجل منح الأم العاملة الحق فى التمتع بحقها في الأمومة

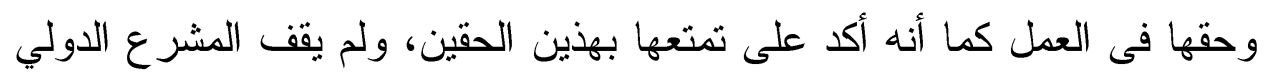

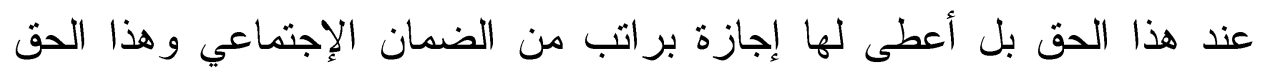
نصت عليه المادة التاسعة من العهد التي اعترفت "بحق كل شخص في الضمان الاجتماعي بما في ذلك التأمين الاجتماعي". حيث بتطلب من الدول الأطراف

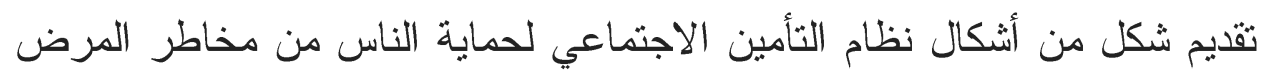

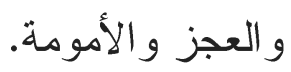

مع العلم بأن مملكة البحرين انضدت للعهد الدولي الخاص بالحقوق الاقتصادية

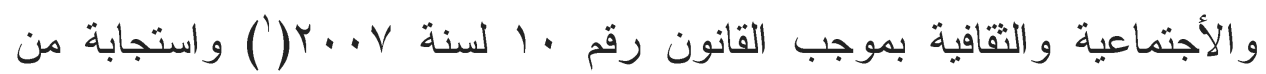
المملكة لتنفيذ تعهاتها نصت المادة الثانية من هذا القانون على "على الوزراءكل فيما يخصه- تتفيذ هذا القانون، ويعمل به اعتبارا من اليوم التالي لتاريخ نشره في الجريدة الرسمية". فمن خلال هذا النص يفرض على وزارة العمل تتفيذ التزامات المملكة الدولية. فيوجب ذلك تعديل تحمل رب العمل كل نفقات الأمومة فهنا الجهة التى تتحمل ذلك هى هيئة التأمينات الاجتماعية بموجب قانونها رقم

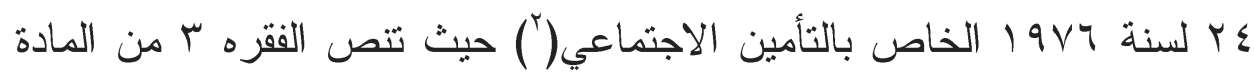

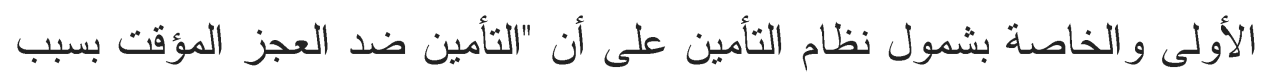

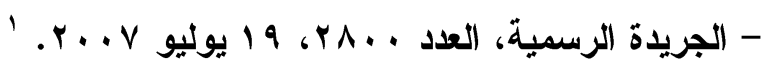

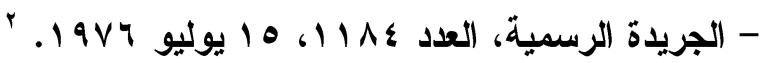


(د.نعيمة فرج عبالنبى) ساعات الرضاعة الطبيعية للام العاملة فى قانون العمل البحرينى

المرض أو الأمومة..." فهنا من المفترض تفعيل هذه الفقرة لأهميتها حتى نصل إلى حماية أكثر للأم و الطفل و المجتمع وضمان اقتصاد حر فعال وناجح.

\section{قائمة المصادرو المر اجع}

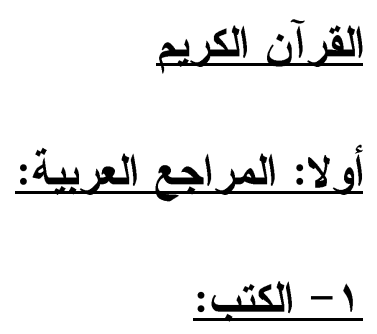

- عدنان خليل التلاوي، القانون الدولي للعمل"شروحات لمنظمة العمل الدولية و التشريع الدولي للعمل 1919-، 1.ب"، المركز العربي السويسري لبحوث التشغيل وحقوق الإنسان فى العمل، جنيف، II ا. Y.

- مريم بنت حسن آل خليفة وعبدالكريم علوان، ملتقى البحرين في حقوق

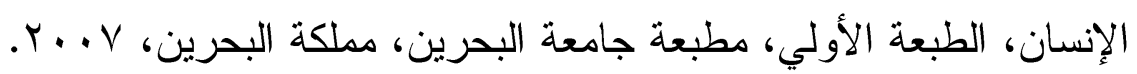

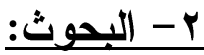

- محمد بورباب، الإعجاز التشريعي في الحث على الرضاعة الطبيعية، مجلة

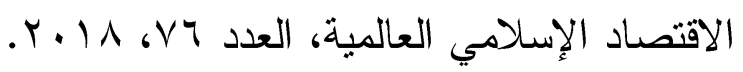


(د.نعيمة فرج عبالنبى) ساعات الرضاعة الطبيعية للام العاملة فى قانون العمل البحرينى

- سامر مظهر قنطقجي، اقتصاد الرضاعة الطبيعية بين الضوابط والمصالح،

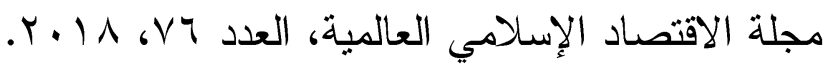
- مخلوف وردة و فسيان حسين، بعض المحددات النفسية والثقافية لممارسة الرضاعة الطبيعية لدى الأمهات، مجلة العلوم الانسانية والاجتماعية، العدد اب ، .$Y \cdot Y V$

- كر ادشة منير، العو امل المؤثرة في الرضاعة الطبيعية فى المجتمع الأردني:

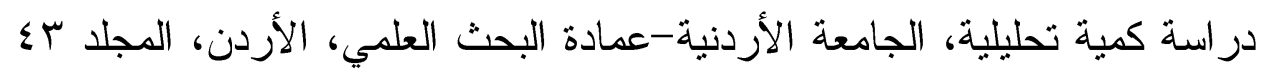
.$r \cdot 17 ،(r)$

- عصام العبد زهد و جمال الهوبى، أثز الرضاعة على العلاقات الأسرية، بحث مقدم إلى مؤتمر كلية الثريعة والقانون ( النتريع الإسلامى ومتطلبات الو اقع)،

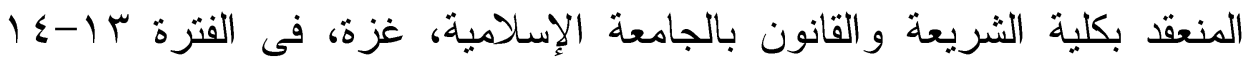
$. r \cdot T / T /$

-عامرمحد علي الأميري (وأخرون)، تأخر النمو الجسمي لدى أطفال الرياض وعلاقته ببعض المتغير ات، مجلة البحوث التربوية، العدد بـ؛، بغداد، ع ا. r. - فاطمة فائق جمعه العاني، تأثير نوع الرضاعة على معدل النمو الجسمي للى

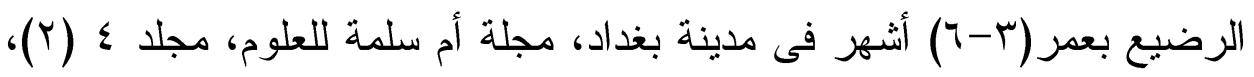

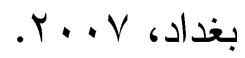


(د.نعيمة فرج عبالنبى) ساعات الرضاعة الطبيعية للام العاملة فى قانون العمل البحرينى

- مريم مال الله غزال وإيمان على هادي، دور التغذية فى مرحلة الطفولة

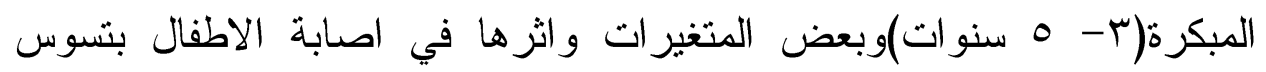

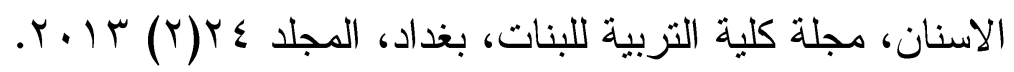

- إيمان قرشى أحمد، النبع الطبيحى للوليد بين القر آن و العلم، معهد بحوث صحة

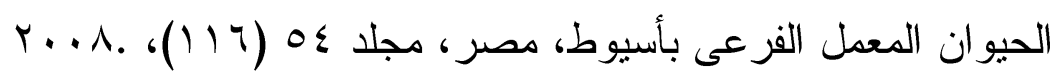

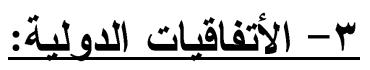

- الإعلان العالمي لحقوق الإنسان 9 19، أعتمد ونشر على الملأ بموجب قرار

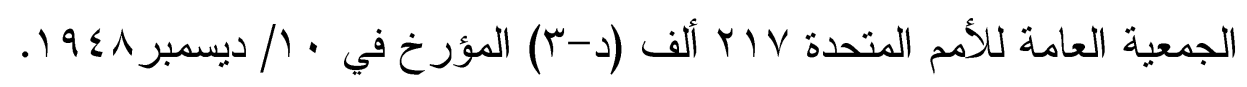
- العهد الدولي الخاص بالحقوق الأقتصادية والأجتماعية و الثقافية ب7971، أعتمد وعرض للتوقيع والتصديق والانضمام بموجب قرار الجمعية العامة - للأمم

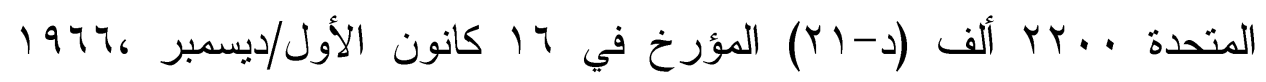

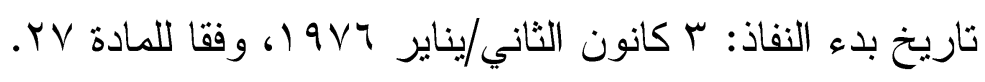

- العهد الدولى الخاص بالحقوق المدنية والسياسية 1974، اعتمد وعرض

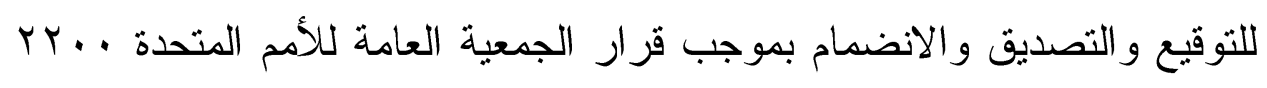

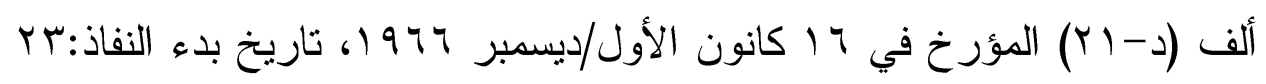

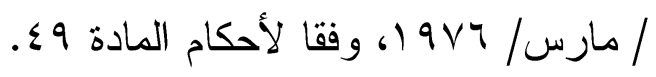


(د.نعيمة فرج عبالنبى) ساعات الرضاعة الطبيعية للام العاملة فى قانون العمل البحرينى

- اتفاقية حقوق الطفل 919 1، عتمدت وعرضت للتوقيع و التصديق والأنضمام

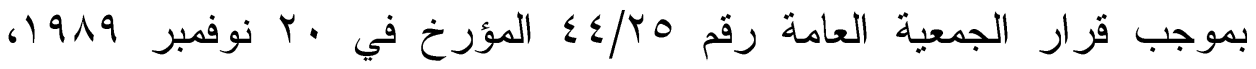
ودخلت حيز النفاذ فى r سبتمبر •99 1، وفقا للمادة 9؛ (1). - أتفاقية القضاء على جميع أثنكال التمييز ضد المرأة 9 ام، اعتمدت وعرضت للتوقيع والتصديق والأنضمام بموجب قرار الجمعية العامة للأمم

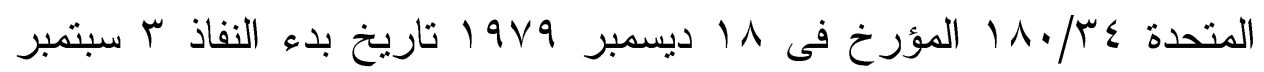

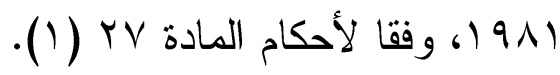
ع - القوانين - دستور مملكة البحرين لسنة ب...r، الجريدة الرسمية، العدد V|OY، ع ||

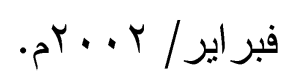
- ميثاق العمل الوطنى لدولة البحرين لسنة ا...ب، الجريدة الرسمية، العدد

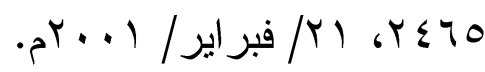

- القانون رقم 17 لسنة (99 1، الخاص بانضمام مملكة البحرين لأثفاقية حقوق

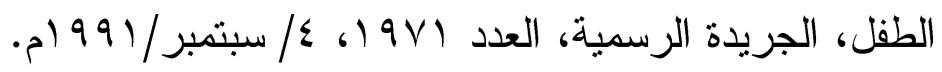


(د.نعيمة فرج عبالنبى) ساعات الرضاعة الطبيعية للام العاملة فى قانون العمل البحرينى

- القانون رقم رقم ه لسنة r ...r، بشأن أنضمام مملكة البحرين لأتفاقية القضاء

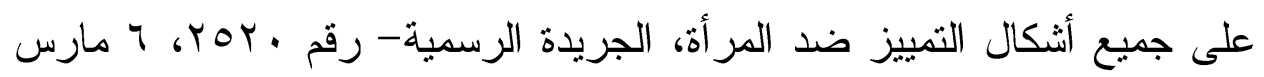
.$r^{\prime} \cdot r$

- القانون رقم 19 لسنة ع ...r، الخاص بانضمام مملكة البحرين إلى البروتوكولين الاختياريين بشأن اشتراك الأطفال في الصراعات المسلحة وبيع بله

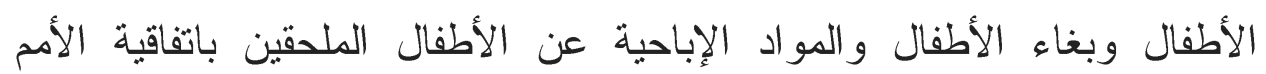

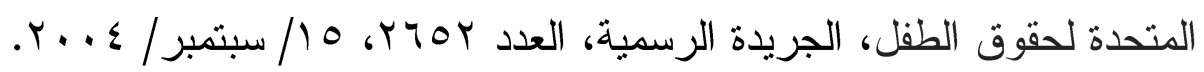
- القانون رقم بr لسنة بVY91، بشأن قانون العمل فى القطاع الأهلى، الجريدة

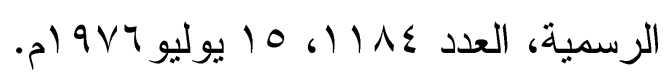

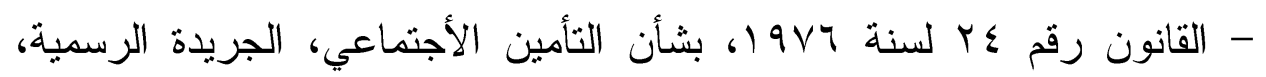

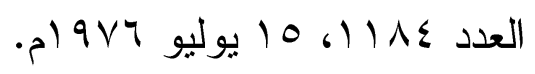

- القانون رقم ع ا لسنة بو99 ابتعديل قانون العمل فى القطاع الأهلى، الجريدة

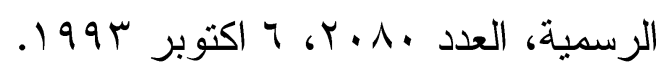

- القانون رقم بr لسنة r ب ـ بشأن قانون العمل فى القطاع الأهلي، الجريدة

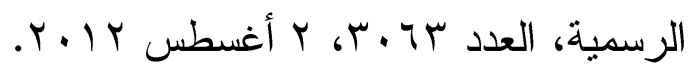


(د.نعيمة فرج عبدالنبى) ساعات الرضاعة الطبيعية للام العاملة فى قانون العمل البحرينى

- القانون رقم • ا لسنة V . . Y، الخاص بمصادقت مملكة البحرين على على العهد الدولي الخاص بالحقوق الأقتصادية والاجتماعية والثقافية، الجريدة

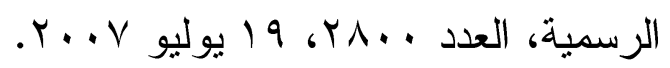

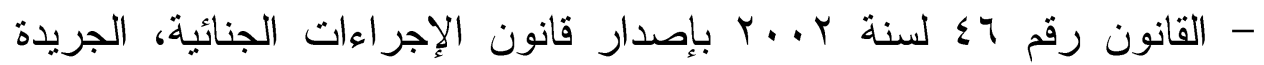

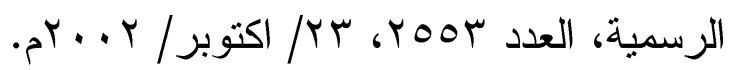

- القانون رقم ^| لسنة ع (. ب بإصدار قانون مؤسسة الإصلاح و التأهيل،

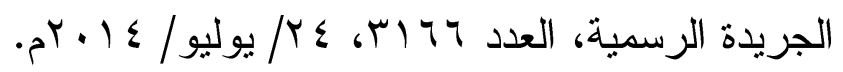

\section{ه-المو اقع الاكترونية}

- منظمة الصحة العالمية، الأسبوع العالمي للرضاعة الطبيعية، مركز وسائل

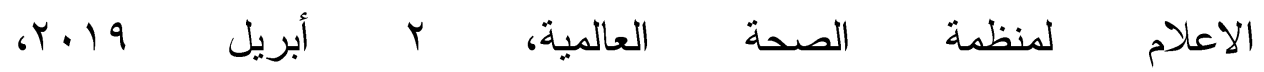
http://www.who.int/mediacentre/events/ . I T/worldLbreastfeeding-week/ar - صحيح مسلم، كتاب الحدود، باب من اعترف على نفسه بالزنى، حديث رقم

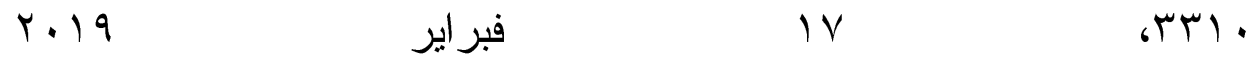
http://www.hadithportal.com/index.php?show=hadith\&h_id=rr 1 \& \&uid $=$ \&\&sharh $=1, \ldots$ \&book $=r \mid \& b a b \_i d=V \leqslant r$ 
(د.نعيمة فرج عبدالنبى) ساعات الرضاعة الطبيعية للام العاملة فى قانون العمل البحرينى

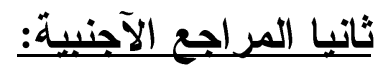

\section{1-Books:}

- Robert Karolis, The Convention on the Rights of the Child:

The Making of a Deception (Bennett's Printing, 199.) ( ${ }^{\top}$ page booklet).

- M Siraj Sait, 'Islamic Perspectives on the Rights of the Child' in Fottrell Deirdre (ed), Revisiting Children's Rights: 1 Y Years of the UN Convention on the Rights of the Child (Kluwer Law International, $r \cdots$...

-Doris E Buss, '"How the UN Stole Childhood": The Christian Right and the International Rights of the Child' in Jo Bridgeman and Daniel Monk (eds), Feminist Perspectives on Child Law (Cavendish, r...).

-Association for Childhood Education International and US National Committee of the World Organization for Early Childhood, 'Global Guidelines for Early Childhood Education and Care in the $r^{\text {st }}$ Century' (ACEI-OMEP, $r \cdots$. . .

-Catherine Marshall and Gretchen B Rossman, Designing Qualitative Research ( $\left.{ }^{\mathrm{rd}} \mathrm{ed}, 1999\right)$.

-Lisa Heap, Maternity Protection ILO Convention No \^r: A New Standard for the New Century (International Confederation of Free Trade Unions (ICFTU), Public Services International (PCI) and Education International (EI), Y . l). 


\section{(د.نعيمة فرج عبدالنبى) ساعات الرضاعة الطبيعة للام العاملة فى قانون العمل البحرينى}

-Uwe Flick, An Introduction to Qualitative Research (SAGE Publications, $r^{\text {nd }}$ ed, $r \cdots r$ ).

-Beverley Hancock, An Introduction to Qualitative Research (Trent Focus Group, 1991)

- Terry Hutchinson, Researching and Writing in Law $\left({ }^{\mathrm{rd}} \mathrm{ed}\right.$, law Book Co of Australasia, $r \cdot 1 \cdot$ ).

-Olena Nizalova, The Economic and Social Consequences of Maternity Protection: A Cross-Country Analysis (LLM Thesis, National University: Kiev-Mohyla Academy, 1999_.$\cdots$. .

-Mahmood Ahmad Ghadanfar, Great Women of Islam: Who were given the good news of paradise, First Edition, Darussalam, Riyadh Saudi Arabia,, ... .

-Robert E Stake, The Art of Case Study Research (SAGE Publications, 1990).

\section{Y-Articles:}

-Daniel Cere, 'Human Rights and the Family' ( $r \ldots q)$ r $r(1)$ Academic Questions. 


\section{(د.نعيمة فرج عبدالنبى) ساعات الرضاعة الطبيعة للام العاملة فى قانون العمل البحرينى}

-Tongzhang Zheng et al, 'Lactation Reduces Breast Cancer Risk in Shandong Province, China' ( $r \cdots$ ) $10 r($ I $r)$ American Journal of Epidemiology.

- Laufey Tryggvadóttir et al, 'Breastfeeding and Reduced Risk of Breast Cancer in an Icelandic' ( $Y . .1) 10 \leqslant(1)$ American Journal of Epidemiology.

-Lawrence M Berger, Jennifer Hill and Jane Waldfogel, 'Maternity Leave, Early Maternal Employment and Child Health and Development in the US' (February $r \ldots .0) 110(0.1)$ Economic Journal Frr.

-Olivia Ball, 'Breastmilk is a Human Right' $(\Upsilon \cdot 1 \cdot) \backslash \wedge(r)$ Breastfeeding Review.

-S Arenz et al, 'Breast-feeding and Childhood Obesity - A Systematic Review' ( $\uparrow \cdots \varepsilon) \uparrow \wedge$ International Journal of Obesity.

-Christopher G Owen et al, 'Effect of Infant Feeding on the Risk of Obesity across the Life Course: A Quantitative Review of Published Evidence' $(r \ldots 0) 110(0)$ American Academy of Pediatrics.

-Diane Whitehead, 'Convention on the Rights of the Child' $(\uparrow \ldots 9) \wedge \circ(\Upsilon)$ Childhood Education. 
(د.نعيمة فرج عبدالنبى) ساعات الرضاعة الطبيعية للام العاملة فى قانون العمل البحرينى

-Laurence M Grummer-Strawn and Zuguo Mei, 'Does

Breastfeeding Protect Against Pediatric Overweight? Analysis of Longitudinal Data from the Centers for Disease Control and Prevention Pediatric Nutrition Surveillance System' ( $\uparrow \ldots \varepsilon)$ $11 \%(r)$ Pediatrics.

-Melissa A Milkie and Pia Peltola, 'Playing All the Roles: Gender and the Work-Family Balancing Act' (1999) 7 ( $(r)$ Journal of Marriage and Family.

-Robin S Mama, 'Needs, Rights, and the Human Family: The Practicality of the Convention on the Rights of the Child' $(\uparrow \cdot 1 \cdot) \wedge \uparrow\left({ }^{\circ}\right)$ Child Welfare.

-Elizabeth J Mayer-Davis et al, 'Breast-Feeding and Risk for Childhood Obesity: Does Maternal Diabetes or Obesity Status

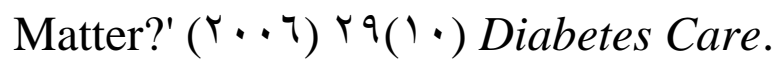

-Laura Addati and Naomi Cassirer, 'Equal Sharing of Responsibilities Between Women and Men, Including CareGiving in the Context of HIV/AIDS' (EGM/ESOR/r . ^ / BP. ${ }^{r}$, Division for the Advancement of Women Department of Economic and Social Affairs United Nations, 19 September $r \cdot . \wedge)$.

\section{r-Thesis:}




\section{(د.نعيمة فرج عبدالنبى) ساعات الرضاعة الطبيعة للام العاملة فى قانون العمل البحرينى}

Cassandra E Sharp, Becoming a Lawyer: the Transformation of Student Identity Through Stories (PhD Thesis, University of Wollongong, $r \cdots$ ? $)$.

\section{$\underline{\text {-Websites: }}$}

Infant and Young Child Feeding: Model Chapter for Textbooks for Medical Students and Allied Health Professionals. Geneva: World Health Organization; $r . .9$. Available from: $r$. Apr. ${ }^{\prime} \cdot \wedge$ https://www.ncbi.nlm.nih.gov/books/NBK। $\{\wedge 970 /$

-Lothian, Judith A. "The Birth of a Breastfeeding Baby and Mother." The Journal of Perinatal Education $1 \leq .1(Y \ldots 0)$ : $\leqslant r_{-}$ \&०.PMC. Web. r Apr. r. 19 . https://www.ncbi.nlm.nih.gov/pmc/articles/PMCl090 r Y/

-Tedros Adhanom Ghebreyesus, Health for all, World Health Organization, $r$ April $r \cdot 19$ http://www.who.int/dg/en 